\title{
El ajuste y las agendas nacionales centroamericanas ${ }^{1}$
}

\author{
Fred Judson ${ }^{2}$
}

\section{Resumen}

Este artículo analiza los orígenes, el impacto y el rumbo de los Programas de Ajuste Estructural (PAE) en Centroamérica. Uno de sus principales argumentos es que, en el marco de los Progiamas de Ajuste Estructural, los Estados de la región se han vuelto, a nivel de autoridad, legitimidad y poder, más dependientes y difusos. Concluye que, en la nueva ortodoxia del mercado, el Estado ha sido juzgado incapaz de alcanzar los objetivos de diversificación, modernización, integración, inclusión y globalización, por lo cual los mismos se han traspasado a las instituciones financieras internacionales, las corporaciones transnacionales y los grandes bloques de capital nacional.

\section{Introducción}

La década de los ochenta fue para Centroamérica de revolución y guerra, pero también sufrió la más severa contracción económica hasta llegar a una depresión clásica. Se iniciaron y aplicaron estrategias y programas de estabilización, ajuste y reestructuración —auspiciadas e impulsadas por fuerzas internacionales - primero en Costa Rica, seguida por Honduras, Guatemala y El Salvador. Nicaragua y Panamá iniciaron el proceso con programas más autóctonos $y$, después de la eliminación forzada del régimen de Noriega, en 1989, y la derrota electoral de los Sandinistas en 1990, estos países se sumaron al menú de Programas de Ajus-

1. Publicado en inglés en Travail, capital et société, Vol. 26, No. 2, noviembre, 1993, p. 148 ss.

2. Profesor del Departamento de Ciencias Políticas de la Universidad de Alberta, Edmonton, Canadá. 
te Estructural (PAE) prescritos para los demás. Para 1990, toda la región ístmica se había empeñado plenamente y los gobiernos se adhirieron a las ideas y las políticas neoliberales que sustentan los Programas de Ajuste Estructural ${ }^{3}$. Basado en entrevistas y publicaciones obtenidas en Centroamérica entre 1992-1993, este ensayo refleja y generaliza la investigación y la opinión de las ciencias sociales en Centroamérica sobre los orígenes, el impacto y el rumbo de esos programas. Se adelantan algunas proposiciones respecto a la formación de agendas nacionales y a las transformaciones de la dependencia en Centroamérica en los años noventa. Las dinámicas determinantes que afectan actualmente a las sociedades centroamericanas son bastante distintas y derivadas de las de los setenta y ochenta, así que, según una amplia variedad de analistas centroamericanos ${ }^{4}$, merecen una teoriración.

\section{El contexto de los Programas de Ajuste Es- tructural: las décadas de los setenta y ochenta}

En los años ochenta se enfrentaron virtualmentc todos los países de la región a una crisis económica estructural, como efecto acumulativo y coyuntural de las recesiones global, regional y nacional. Se combinaron los numerosos aspectos de las crisis, como la descapitalización, la inflación, el aumento en el desempleo y subempleo, la caída del consumo per cápita de bienes básicos, la caída de precios por los productos de exportación, una excesiva dependencia en la importación estratégica, la militarización costosa, los déficits presupuestarios y las cargas pesadísimas de la deuda externa. Esa combinación de factores hizo aparentamente imposible un desarrollo nacional capitalista significativo para la mayoría, o un socialismo que no iba más allá de la escasez compartida. Las situaciones fueron descritas en varios términos: crisis estructural de acumulación, crisis del modelo agroexportador, crisis del Estado intervencionista neokeynesiano y crisis del capitalismo dependiente periférico.

Las condiciones y los procesos revolucionarios, las guerras civiles, la intervención foránea que, conjuntamente causaron tanta muerte, destrucción y dislocación social en los años setenta y ochenta, tienen una relación causal y parcial, sino total, con las experiencias distorsionadas de la agroexportación, el crecimiento rápido y la industrialización dependiente de las décadas de los cincuenta, sesenta y setenta. La concentración excesiva de capital, el tlujo transnacional de capital proveniente del exterior, el endeudamiento galopante en los años posteriores, el comercio internacional desigual, la distribución sesgada del ingreso y de la propiedad productiva, la urbanización acelerada y empobrecida caracterizaron el desarrollo económico de esos años. Cualesquiera que sean las apreciaciones académicas y políticas de causalidad, no se puede negar la profundidad de la crisis económica en los ochenta. Para citar una autoridad competente, "para Centroamérica, los ochenta... representan la peor crisis en su historia posindependencista... el Producto Interno Bruto per cápita en 1990 todavía se mantenía bajo los niveles de 1980 en las cinco repúblicas"s.

Estudios autorizados en inglés ${ }^{6}$ sobre las experiencias de desarrollo nacional y regional en Centroamérica, en la época de la segunda postguerra

3. Belice es un país centroamericano, sin embargo, no lo comento en este artículo. Para una introducción amplia sobre Belice, ver Barry, Tom, Inside Belize, Albuquerque: Inter-Hemispheric Education Resource Center, 1992.

4. Ver Gallardo, Helio, "Radicalidad de la teoría y sujeto popular en América Latina", Pasos, No. 3, Número Especial, San José: Departamento Ecuménico de Investigación, 1992, pp. 27-42. Entrevista a Helio Gallardo, teólogo y politólogo, del Departamento Ecuménico de Investigación, San José, Costa Rica, el 23 febrero 1993.

5. Bulmer-Thomas Victor, "A Long-run Model of development for Central America", Occasional Papers, No. 27, Institute of Latin American Studies, London: University of London, 1991, p. 1. Alguna mejora se evidenciaba en los indicadores costarricenses; los de Guatemala, Honduras y El Salvador por lo menos se aproximaban a la stagnación estable y los de Nicaragua seguían en declive agudo.

6. Ver Dunkerley, James, Power in the Isthmus: A Political History of Modern Central America, London: Verso, 1988; Bulmer-Thomas, Victor, The Political Economy of Central America Since 1920, London: Cambridge University Press, 1987; Barry, Tom, Central America Inside Out, Nueva York: Grove Weidenfeld, 1991; Booth, John y Walker, Thomas, Understanding Central America, 2a. Edición, Boulder: Westview, 1993; Stirton Weaver, Frederick, Inside the Volcano: The History and Political Economy of Central America, Boulder: Westview, 1994. 
mundial, tienden a buscar causalidad de la doblecrisis (cconómica y política) de los setenta y ochenta en los modelos económicos prevalecientes. Asimismo, las ciencias sociales centroamericanas, en gran medida, y a pesar de sus discrepancias ideológicas y de la proliferación de "posismos", mantienen un enfoque analítico en el concepto del desarrollo/subdesarrollo capitalista dependiente y periférico. Ese capitalismo dependienle centroamericano se concibe como distorsionado, desnivelado, extrovertido y, muy importante para la mayoría de la teorización social centroamericana, subordinado a los patrones de una hegemonía estadounidense sobre la región.

Así como el carácter de esa hegemonía, muchas veces nombrada imperialismo, se prestaba a las explicaciones de los conflictos político-militares de los setenta y ochenta, así ha sido central en el análisis y la explicación de las sociedades y estados centroamericanos en el período actual de ajuste estructural. Con todo, los procesos colectivamente llamados "reestructuración" y "globalización", imponen un replanteamiento que se reconoce en gran parte de la investigación actual sobre Centroamérica. No se trata de que la hegemonía estadounidense y la dependencia de las economías centroamericanas hayan desaparecido, sino que los contextos para teorizar esas globalidades han cambiado y siguen cambiando de manera significativa?.
En efecto, nadie rechaza la caracterización de la década de los ochenta como una de crisis económica, ni aboga en contra de la necesidad de alguna forma de estabilización, ajuste y reestructuración. Como observó el presidente costarricense, Carlos Monge, en 1984: "con el Fondo Monetario o sin él, de todas formas era indispensable que hiciéramos el ajuste estabilizador de la economía... Sin este ajuste, por doloroso e ingrato que haya sido, Costa Rica [y por extensión, los demás países centroamericanos] habría sido arrollada por la turbulencia social"'. Además, existe un consenso de que: $(a)$ a la reestructuración significativa de las economías centroamericanas tendría que seguir una estabilización inicial y el ajuste consecuente, por ejemplo, que no se podría volver a un estatus quo ante; y $(b)$ que, como sucedería de todas maneras, sería probable que los países centroamericanos tendrían que acomodarse a los perfiles de las tres fases del ajuste generalmente propuestas, impuestas e implementadas, según las directivas del Fondo Monetario Internacional, del Banco Mundial y de la Agencia Internacional de Desarrollo (AID) ${ }^{9}$. De todos modos, no había otras fuentes de crédito o fondos para la estabilización y, definitivamente, estos no vendrían de los bancos privados.

\section{El ajuste implementado}

Los gobiernos y las élites centroamericanas

7. Ver Hinkelammert, Franz, "La Lógica de la expulsión del mercado capitalista mundial y el proyecto de liberación”, Pasos, No.3, San José: Departamento Ecuménico de Investigación, 1992, pp. 3-21; y Guerra-Borges, Alfredo, "Globalización y regionalización", CRIES, Anuario Centroamérica 1994, Managua: Coordinadora Regional de Investigación Económica y Social, 1994, pp. 51-53.

8. Citado en Sojo, Carlos, La utopia del estado mínimo. Influencia del Agencia Internacional de Desarrollo en Costa Rica en los años ochenta, Managua: CRIES, 1991, p. 30.

9. Las entrevistas que reflejan el consenso incluyen: Gerardo Timossi, Director de Investigación, CRIES, Managua, fechas varias, octubre 1992-abril 1993; Arturo Gallese, Director Ejecutivo, CRIES, Managua, fechas varias, octubre 1992-abril 1993; Ian Walker, Profesor de Economía, Programa Postgrado, Universidad Nacional Autónoma de Honduras, Tegucigalpa, 8-12 de noviembre de 1992; Dr. Marco Gandásegui, Secretario Ejecutivo, Centro de Estudios Latinoamericanos, Panamá, 11 de enero de 1993; Dr. Iván Quintero, Profesor de Economía, Universidad de Panamá, 12 de enero de 1993; Dr. Edelberto Torres-Rivas, Director, FLACSO, San José. 18 de febrero de 1993; Roberto Rubio, Director de Investigación, FUNDE (Fundación Nacional para el Desarrollo), San Salvador, 18 marzo de 1993; Dr. Rubén Zamora, Vicepresidente de la Asamblea Legislativa, San Salvador, 22 de marzo de 1993; Werner Ramírez, economista, AVANCSO (Asociación para el avance de las ciencias sociales en Guatemala), Guatemala, 30 de marzo de 1993; Dr. Alfonso Portillo, Director, Instituto Guatemalteco de Estudios Políticos, Guatemala, 29 de marzo de 1993. 
concluyeron que existía una crisis económica intratable y empezaron a aplicar las medidas prescritas en las cuales encontraron un alivio inmediato. Al aceptar los diagnósticos de las instituciones financieras internacionales, de los consorcios públicos y privados de prestamistas y de la Agencia Internacional de Desarrollo se les entregaron los fondos de estabilización, préstamos "puente" y una renegociación de la deuda externa o reprogramación de sus pagos. Los componentes, individualmente diseñados, de los paquetes de estabilización, cuya entrega dependía del compromiso del país al curso completo de los Programas de Ajuste Estructural, establecieron la lógica de reestructuración en las políticas fiscales y monetarias (y de extensión las sociales) del Estado respectivo ${ }^{10}$. Así que la contracción económica existente en las agendas nacionales y la deliberación política que definiera las alternativas dentro de esas agendas, se complicó y agudizó. En ese sentido, la triple dependencia que marcaba la situación global de Centroamérica -el modelo agroexportador, el financiamiento presupuestario y las inversiones por deuda internacional, así como la hegemonía político-militar de Estados Unidos- ahora fue alterada y sobrecargada por los Programas de Ajuste Estructural.

Las medidas implícitas en los paquetes de estabilización y reforzadas bajo los Programas de Ajuste Estructural otorgados a cada Estado, empezando con Costa Rica en 1983'I, abarcan una agenda bastante conocida, que se aplicaron en una veintena de países por todo el mundo. En general, las medidas incluyen cortes profundos en los presupuestos y gastos públicos, devaluación de la moneda nacional, privatización de empresas y servicios estatales, liberalización del comercio internacional y repliegue del Estado de toda una gama de intervenciones en el mercado. En cada caso centroamericano se despidieron decenas de miles de empleados públicos; los servicios sociales sufrieron una contracción severa cuando no su desaparición total, particularmente en salud, educación y bienestar; y se han quilado los subsidios y otros apoyos estatales a la agricultura e industria. En efecto, "el sueldo social" y "las inversiones sociales" han sido drásticamente reducidos, si no eliminados. Además, el control estatal del mercado de trabajo se acortó, y la "desregulación" en esa esfera ha colocado a la fuerza laboral más directamente bajo "las leyes del mercado". En la práctica, esas leyes han abaratado el trabajo, dado que la oferta laboral ha aumentado sin un incremento correspondiente en la demanda, mientras los precios de las bienes básicos han subido. En contraste, el consumo y el capital han experimentado un incremento en su valor social relativo, sus precios y su prioridad estructural.

En la práctica, las tres fases de los Programas de Ajuste Estructural —estabilización, ajuste y reestructuración - no han sido claramente demarcadas en Centroamérica. La expectativa de los teóricos, planificadores nacionales y administradores internacionales de los Programas de Ajuste Estructural, generalmente era que los "shock" requeridos para adquirir los recursos de estabilización contenían "mapas genéticos-DNA". Esos mapas llevarían a Centroamérica directamente a unas economías radicalmente reestructuradas, completamente mercantilizadas y competitivas, con un papel positivo en la nueva división global de trabajo. Así que la fase del ajuste sería la de cambios fundamentales y esenciales en las políticas fiscales, monetarias y económicas que fueran ejecutadas por el Estado, en tanto que en el sector privado surgieran nuevas inversiones y estrategias de acumulación. El ajuste supuestamente contiene e inicia los programas y los procesos que ordenarán y caracterizarán a un "nuevo" patrón de desarrollo que emerja en la fase de reestructuración ${ }^{12}$. En la prác-

10. Para un repaso comparativo de los Programas de Ajuste Estructural centroamericanos en los ochenta y una teorización inicial de la lógica de la reestructuración de la deuda externa, ver Timossi Dolinsky, Gerardo, Centroamérica: deuda externa y ajuste estructural; las transformaciones económicas de la crisis, Managua: CRIES, 1989.

11. Para mayor información sobre los Programas de Ajuste Estructural en Costa Rica, ver Li Kam, Hess y Cedeño, "La Promoción del nuevo estilo de desarrollo en Costa Rica", Avances de Investigación No. 3, Instituto de Investigaciones Sociales, San José: Universidad de Costa Rica, 1992; Franco, Eliana y Sojo, Carlos, Gobierno, cimpresarios y políticas de ajuste, San José: FLACSO, 1992.

12. Para mayor información sobre estos programas y procesos centroamericanos, ver Stein, Eduardo y Arias Peñate, Salvador. eds. Democracia sin pobreza; alternativa de desarrollo para el istmo centroamericano. San José: Departamento Ecuménico de Investigación, 1992. 
tica, tanto los gobiernos centroamericanos como las agencias internacionales que planifican, financian e aplican los Programas de Ajuste Estructural, han tenido que "amortiguar" los choques del ajuste que más han afectado a la mayoría de la población. Eso se traduce en la moderación, en los casos de Costa Rica, Guatemala y Honduras, de la liberalización estricta de los precios de consumo y la puesta en marcha de programas nombrados "la compensación social" 13 . En Honduras, esto se concoce como "el ajuste al ajuste"14. Y en toda la región, los cortes o la eliminación total de subsidios en la agricullura "tradicional" para la exportación o el consumo nacional, frecuentamente han sido reemplazados por subsidios de la Agencia Internacional de Desarrollo a sectores exportadores "no-tradicionales", como el camarón y el melón en Honduras, las plantas ornamentales y las flores en Costa Rica, el brócoli y los chícharos en Guatemala ${ }^{15}$.

Sin embargo, no se debe subestimar el impacto de los Programas de Ajuste Estructural y de las políticas económicas y sociales incluidas. Aunque los Programas de Ajuste Estructural no funcionan en un vacío, han sido el centro del desmantelamiento de las infraestructuras más desarrolladas del "welfare state" (estado de 'bienestar') de la región centroamericana y Panamá. Lo anterior se ha combinado con otros factores para acelerar y profundizar la inversión de los programas económicos y sociales del período revolucionario Sandinista en Nicaragua. En El Salvador, la aplicación de los Programas de Ajuste Estructural y la aceptación de sus premisas, si no sus consecuencias, dada la presión de las fuerzas políticas orga-

nizadas del país, han contribuido a que muchos salvadoreños, simpatizantes del FMLN en la guerra civil, hayan perdido la confianza en cualquier forma de desarrollo nacional colectivo ${ }^{16}$.

Además, la carga de la deuda externa, o sea, las condiciones de los pagos, ha sido aliviada por todos los Estados centroamericanos, porque la aceptación de los Programas de Ajuste Estructural ha llevado a la renegociación y al acceso a nuevos créditos. Las crisis fiscales se han mitigado. La inflación crítica - ni hablar de la hiperinflación nicaragüense de los años ochenta posteriores- no ha marcado a los noventa. Ha ocurrido una vuelta significativa, aunque selectiva, del "capital expatriado" que salió de la región por una variedad de motivos en los ochenta. La liberalización del comercio internacional ha generado un aumento de la importación, no solamente de bienes de consumo sino de bienes de capital. Inversiones mayores en el sector de la maquila han revitalizado o creado "polos de desarrollo", como en el corredor San Pedro Sula-Puerto Cortés, en el norte de Hondu-

13. El caricaturista guatemalteco Filóchofo, entre muchos, se ha divertido ampliamente con el concepto de la "compensación social". Ver El Año de la compensación social, Guatemala: arte, color y texto, S.A., 1992.

14. Entrevista a Hugo Noé Pino, Presidente del Colegio Hondureño de Economistas, Tegucigalpa, el 13 noviembre de 1992; Hernández, Alcides, "El ajuste estructural y sus repercusiones económicas y sociales". Especial CEDOH No. 58, Tegucigalpa: Centro de Documentación de Honduras, 1991.

15. Para mayor información sobre los casos guatemaltecos y costarricenses, ver la entrevista a Manuel Solís, Director del Instituto de Investigaciones Sociales, Universidad de Costa Rica, San José, el 24 de febrero de 1993. Ver Sojo, Carlos, La Mano visible del mercado; la asistencia de Estados unidos al sector privado costarricense en la década de los ochenta, Managua: CRIES, 1992; y Escoto, Jorge y Marroquín, Manfred, La Agencia Internacional de Desarrollo en Guatemala; poder y sector empresarial, Managua: CRIES, 1992.

16. Ver Guido Béjar, Rafael, "El tiempo del adiós; la izquierda y el cambio social en El Salvador", Polémica, No. 16, San José: FLACSO, 1992, pp. 3-12. 
ras, en los alrededores de San José, Costa Rica y Chimaltenango, en las afueras de la ciudad de Guatemala. De Panamá, en el sur, hasta El Salvador y Guatemala, en el norte, los servicios financieros, los bancos, el transporte y ciertos sectores de la agroexportación han florecido en las condiciones parcialmente creadas por el ajuste y la reestructuración. Ha habido alguna recuperación y expansión del comercio regional después del desbarate de las guerras, la intervención externa y la parálisis del Mercado Común Centroamericano ${ }^{17}$. El comercio interregional, especialmente con México $^{18}$, pero también con las regiones sudamericanas, ha mostrado crecimiento. En breve, las economías nacionales y regionales han experimentado cierta reactivación bajo los regímenes Programas de Ajuste Estructural; las crisis características de los ochenta ya no azotan de la misma manera.

\section{La hegemonía, la política de Estados Unidos y los PAE}

Como previamente se ha mencionado, la mayoría de la ciencias sociales centroamericanas comparten dos premisas iniciales: (1) que la economía política de la región se entiende mejor como un capitalismo dependiente, y (2) que el marco fundamental de tanto la economía como la política regional es la hegemonía estadounidense. Entonces, en el empeño de estudiar la economía política del ajuste/recstructuración, las ciencias sociales tienden a postular y teorizar con base en las dos premisas.

El discurso mayoritario científico-social de las últimas tres décadas en Centroamérica ${ }^{19}$ enfatiza en los motivos imperiales o hegemónicos de Estados Unidos, como causantes principales de las más importantes dinámicas económicas en la región. Así que esos motivos jugaron un papel innegable en el inicio e implementación de los Programas de Ajuste Estructural. Un financiamiento sustancial de Estados Unidos, en la forma de Economic Support Funds (ESF) - Fondos de Apoyo Económico- y otro financiamiento de la
Agencia Internacional de Desarrollo, llegaron para estabilizar a los gobiernos como tales, tanto o más que a las economías respectivas, desde el momento en que esos gobiernos aceptaron a los Programas de Ajuste Estructural -primero Costa Rica, Honduras y El Salvador, después Nicaragua, Guatemala y Panamá. En la interpretación predominante, los intereses políticos y estratégicos y la agenda de Estados Unidos por la región, no sólo pesaron más que los diagnósticos estrictamente económicos de las crisis estructurales, sino que dictaron la prescripción y aplicación de los Programas de Ajuste Estructural. Esos intereses van desde el deseo benigno de tener "la estabilidad política en el traspatio de Estados Unidos" por "la reestructuración de la hegemonía" después de los retos revolucionarios, hasta "la detención de la democracia" para defender unos sistemas sumamente rentables, sistemas de explotación y orden políti$\mathrm{co}^{20}$.

Más en concreto, se plantea que el derrocamiento de los Sandinistas en Nicaragua, la derrota militar del FMLN en El Salvador, el cese en el avance del movimiento revolucionario armado en Guatemala y la contención de cualquier radicalización en Centroamérica fueron los objetivos principales de Estados Unidos. Por eso, lo que se llamaba "conflicto de baja intensidad" incluía el despliegue de unos "engatusamientos" económicos, tales como fondos de estabilización, refinanciamiento de la deuda externa y los Fondos de Apoyo Económico. En este escenario se les asignó a ciertos países un papel específico para lograr los objetivos hegemónicos y contrarrevolucionarios. Honduras, por supuesto, recibió ayuda masiva en el campo militar que le permitió convertirse en contrapeso estratégico contra Nicaragua. Además, el primero contaba con bases que fueron utilizadas como retaguardia de los contras nicaragüenses, y también como apoyo potencial para la intervención directa de Estados Unidos contra el FMLN en El Salvador ${ }^{21}$. Honduras también fue anfitrión en las repetidas maniobras militares estadounidenses;

17. Ver la sinopsis en CRIES, Anuario Centroamérica 1994, Managua: CRIES, 1994, pp. 16-22.

18. Ver H. Rodrigo Jauberth Rojas, et al., La triangulación Centroamérica-Mexico-EUA ¿una oportunidad para el desarrollo y la paz?, San José: Departamento Ecuménico de Investigación, 1991.

19. Ver Liss, Sheldon, Radical Thought in Central America, Boulder: Westview, 1991.

20. Ver Chomsky, Noam, Deterring Democracy, New York: Hill y Wang, 1992.

21. Ver Salamón, Leticia, Política y militares en Honduras, Tegucigalpa: CEDOH, 1992; Meza, Víctor, Honduras: pieza clave de la política de Estados unidos en Centroamérica, 3a ed., Tegucigalpa: CEDOH, 1990. 
éstas, junto con las bases militares permanentes, fueron interpretadas en la región como precursoras del ataque directo de Estados Unidos contra Nicaragua, si los contras y las otras dimensiones del "conflicto de baja intensidad" fallaban. Respetados analistas hondureños, quienes reconocieron que la aplicación de los Programas de Ajuste Estructural en Honduras tenía cierta derivación doméstica, señalaron los motivos políticos y estratégicos de Estados Unidos como el contexto determinante, por lo menos en las etapas inciales, en los ochenta ${ }^{22}$. A partir de esta interpretación, el "retorno a la democracia", después de los regímenes militares auspiciados por Estados Unidos, era bastante frágil y requería de un fortalecimiento económico.

Si Honduras era "la pieza clave" (la frase es de Víctor Meza ${ }^{23}$ en la política de Estados Unidos para contener e invertir en la revolución nicaragüense, Costa Rica tenía un papel no menos importante pero más estrictamente político. Costa Rica era "el escaparate de la democracia" en la región. Estados Unidos no podría permitir que ese estatus se desgastara. Sin embargo, la amenaza de un deterioro crecía en los últimos años de los setenta, y los primeros de los ochenta, cuando la crisis económica estremecía la famosa estabilidad social costarricense. El presidente costarricense, Carlos Alberto Monge, elegido en 1982, no se tardó en subrayar la convergencia de los intereses estratégicos estadounidenses en la región con la estabilización económica. Su insistencia se convirtió en la conexión norteamericana con las agencias financieras internacionales, lo que produjo el primer Programa de Ajuste Estructural negociado entre Costa Rica y el Fondo Monetario Internacional en enero de $1983^{24}$. Hay evidencia de que la administración Reagan, de manera independiente, llegó a la misma conclusión que Monge; era preciso upoyar a Costa Rica, como elemento en el mantenimiento del control estratégico regional. Era preciso mostrar un "escaparate de la democracia" como un contraste a "la tiranía sandino-comunista"; Costa Rica funcionaba como apoyo ideológico al sistema de control ${ }^{25}$ diseñado por Estados Unidos. Así fue que los préstamos y la ayuda oficial comenzaron a desembolsarse por parte del gobierno estadounidense, principalmente en la forma de los Fondos de Apoyo Económico (ESF). Entre 1982 y 1990, los Fonos de Apoyo Económico sumaban 74 por ciento del total de la ayuda estadounidense entregada a Costa Rica ${ }^{26}$. Los ESF fueron cruciales; entre 1983-85, "la ayuda estadounidense cubría 35.7 por ciento del presupuesto estatal"27. El patrón del ajuste en Costa Rica en los ochenta, según opinión predominante en las ciencias sociales, se entiende cuando se incluye en el contexto de la hegemonía estadounidense.

Durante los ochenta, El Salvador fue la ubicación curiosa, en términos políticos y militares, del más sofisticado movimiento revolucionario latinoamericano: el FMLN28. Con la población más concentrada y el territorio más pequeño en la región, casi sin zonas remotas, las normalmente consideradas propicias para la guerrilla, El Salvador se aproximaba al triunfo revolucionario armado. Se entiende que Estados Unidos comprometiera miles de millones de dólares durante la década, en forma combinada de ayuda económica y militar, para prevenir tal conclusión a la guerra civil en El Salvador. La ayuda directa militar - las armas y pertrechos, los programas de capacitación y asesores - vino acompañada por una variedad amplia de programas de la Agencia Internacional de Desarrollo. Esos programas, incluso los ESF, sumaban más de un millón de dólares diarios ${ }^{29}$. Por un

22. Entrevistas a Víctor Meza, Director de CEDOH, Tegugigalpa, 12 de noviembre de 1992; Mario Posas, Profesor de Ciencias Políticas de la Universidad Nacional Autónoma de Honduras, Tegucigalpa, el 9 noviembre de 1992; Francisco Díaz Chávez, historiador y Profesor de Ingeniería de la Universidad Nacional Autónoma de Honduras, Tegucigalpa, el 12 de noviembre de 1992; Guillermo Molina, sociólogo y director, Centro de Estudios y Promoción de Desarrollo, Tegucigalpa, el 10 de noviembre de 1992.

23. Meza, Víctor, 1990.

24. Li Kam, et. al., op. cit, p. 3.

25. Sojo, Carlos, 1991, op. cit., pp. 18-19.

26. Ibíd., pp. 33.

27. Dunkerley, James, op. cit., p. 636.

28. Castañeda, Jorge, Utopia Unarmed: the Latin American Left After The Cold War, New York: Vintage, 1994; presenta una evaluación del éxito del FMLN.

29. Barry, Tom, El Salvador: A Country Guide, 2a ed., Albuquerque: The Inter-Hemispheric Resource Center, 1991, p. 143. 
margen sustancial, El Salvador fue el receptor de más ayuda que cualquier otro país en la región y, se podría decir, el más penetrado por la Agencia Internacional de Desarrollo y otras agencias estadounidenses ${ }^{30}$.

Guatemala es considerado por muchos analistas el "premio" más rico de la región. Ello se debe a su economía agroexportadora sustancial; su potencialidad en la minería y los hidrocarburos; el nivel más alto de inversiones privadas estadounidenses, después del caso especial de sector financiero panameño ${ }^{31}$; su capacidad industrial relativamente más avanzada y su mayor mercado doméstico. Pero Guatemala desempeñó una función menor en las consideraciones estratégicas estadounidenses durante los ochenta. Aunque las organizaciones revolucionarias que operaron en conjunto en la Unidad Revolucionaria Nacional Guatemalteca (URNG) aparentemente eran una amenaza militar, dado su apoyo popular, en los años 19781981, las Fuerzas Amadas de Guatemala, hacia 1982, habían aplastado a la guerrilla con una feroz represión. Los militares guatemaltecos lo hicieron con menor ayuda estadounidense que la entregada a Honduras y El Salvador, aunque recibieron el apoyo moral de la administración Reagan ${ }^{32}$. Después de 1983 se incrementaron ambas formas de ayuda norteamericana, la económica y la militar, la primera orientada a consolidar y ampliar la agenda de la estabilización y el ajuste en Guatemala. La ayuda económica entre 1980 y 1992, según un estudio, sumaba arriba de un mil millones de dólares, la mayoría en programas de la Agencia Internacional de Desarrollo ${ }^{33}$. Y aunque al analizar el ajuste y la reestructuración los científicos sociales en Guatemala fueron cautelosos en señalar la autonomía de la economía política guatemalteca de la dinámica doméstica de acumulación y la agenda de política pública, coincidieron en identificar a la política estadounidense de ayuda como un determinante central en los ochenta y en la actualidad ${ }^{34}$.

El caso de Panamá representa un contraste marcado al contemplar el papel de la hegemonía estadounidense en las experiencias centroamericanas del ajuste y reestructuración. La diferencia radica en el hecho de que Panamá sufrió unas sanciones económicas sostenidas, casi una agresión en sí, durante los dos años previos a la invasión estadounidense de 1989. Indudablemente, algunas dimensiones de la crisis que ocurrían en el resto de la región golpeaban a la economía panameña antes de la ruptura final entre el gobierno de Manuel Noriega y Estados Unidos. Sin embargo, la opinión dominante entre analistas panameños era que las sanciones llevaron a la economía a un punto de colapso ${ }^{35}$. Se estima que los costos y las pérdidas en la economía, debidos a las sanciones y la invasión, sumaron entre 3 y 10 mil millones de dólares ${ }^{36}$. Fue después de la invasión, durante el gobierno de Guillermo Endara - quien en las elecciones de 1994 ganó el Partido Revolucionario Democrático, nominalmente el partido de gobierno durante la época de Noriega- que las políticas

30. Para mayor información, ver Rosa, Hermán, Agencia Internacional de Desarrollo y las transformaciones globales en El Salvador, Managua: CRIES, 1993.

31. Barry, Tom, Inside Guatemala: The Essential Guide to its Politics, Economy, Society and Environment, Albuquerque: Resource Center, 1992, p. 259.

32. Para discusiones sobre la ayuda militar y económica en el contexto de la estrategia regional estadounidense, ibid., esp., pp. 261-277.

33. Escoto, Jorge y Marroquín, Manfredo, Agencia Internacional de Desarrollo en Guatemala: poder y sector empresarial, Guatemala: CRIES? AVANCSO, 1993, p. 135.

34. Entrevistas representativas incluyeron a Werner Ramirez, economista, AVANCSO, Guatemala, 30 de marzo de 1993; Carlos López, economista, Instituto Guatemalteco de Estudios Políticos, Guatemala, 30 de marzo de 1993; Luis Solano, periodista y Director de Información, Inforpress, Guatemala, 26 de marzo de 1993.

35. Ver Jované, Juan, "Ajuste, nación y sociedad civil”, Tareas, No. 80, Panamá: Centro de Estudios Latinoamericanos "Justo Arosemena", enero-abril, 1992, pp. 59-65; Cordero, Alejandro, Ensayos sobre la crisis económica panameña 1988-1990, Panamá: Instituto de Estudios Nacionales, Universidad de Panamá, 1991; Entrevistas que corraboran esta conclusión incluyen a Ivan Quintero, economista, Universidad de Panamá, 12 de enero de 1993; Jorge Castillo, economista y director, Centro de Investigación y Docencia, Universidad de Panamá, 13 de enero de 1993; Juan Jované, economista, Universidad de Panamá, 15 de enero de 1993; Ricaurte Soler, historiador, Universidad de Panamá, 15 de enero de 1993.

36. Zimbalist, Andrew y Weeks, John Panama at the Crossroads: Economic Development and Political Change in the Twientieth Century, Berkeley: University of California Press, 1991, p. 165. 
de ajuste, ligeramente iniciadas en 1980, maduraron ${ }^{37}$. Para Ricaurte Soler, el historiador mejor conocido en Panamá, la invasión y la siguiente aplicación de los Programas de Ajuste Estructural auspiciados por la Agencia Internacional de Desarrollo y las Instituciones Financieras Internacionales (IFI's) constituyen "el neocolonialismo postguerra fría" 38 . Solamente como tal se pueden entender, afirma Soler ${ }^{39}$.

Hasta la derrota electoral de los sandinistas en 1990, Nicaragua, como Panamá, fue considerada por Estados Unidos como un enemigo. Como tal, no era elegible para los Programas de Ajuste Estructural, auspiciados por la Agencia Internacional de Desarrollo o las Instituciones Financieras Internacionales. Además, Nicaragua constituía el blanco de sanciones económicas, sabotajes y la agresión diplomática y militar por parte de Estados Unidos. Tanto antes como después de la elecciones de 1990, los sandinistas culparon a esa "guerra de baja intensidad" de la ruina económica. Como es bien sabido, La Corte Internacional de Justicia en La Haya compartió ese criterio y, hasta después de la llegada a la presidencia de Violeta Chamorro, Nicaragua mantenía un juicio por reparaciones contra Estados Unidos por un valor de $17 \mathrm{mil} \mathrm{mi-}$ llones de dólares ${ }^{40}$. Obviamente, la guerra, que dominaba a la política económica sandinista durante los ochenta, no solamente exacerbó las distorsiones económicas de la época somocista, sino que también socavó los programas desarrollistas de los sandinistas, considerados débiles por muchos analistas; y a partir de 1985, la economía se convirtió en una economía de guerra, con las consecuencias bien conocidas y documentadas.

Aun en medio de la guerra, en 1987, el gobierno sandinista comenzó lo que se denominó "el ajuste sin fondo", una frase cargada con distintos sentidos: sin dinero, sin el Fondo Monetario Inter- nacional y sin fin. Hubo, de facto,programas de lu Agencia Internacional de Desarrollo de apoyo al sector privado en Nicaragua durante los ochentu. pero fue solamente con la elección del gobierno UNO-Violeta Chamorro, en 1990, que el menú completo de los Programas de Ajuste Estructural, auspiciados por la Agencia Internacional de Desarrollo, se aplicó. Actualmente, aunque se podría plantear que la agenda de la Agencia Internacional de Desarrollo haya superado los objetivos de la "guerra de baja intensidad" y las prácticas contrarrevolucionarias y de Guerra Fría de las administraciones Reagan y Bush, las ciencias sociales críticas en Nicaragua siguen en la percepción de que los Programas de Ajuste Estructural son parte integrante de una reestructuración hegemónica ${ }^{41}$.

Al terminar la década de los ochenta, los motivos políticos de Estados Unidos para impulsar los programas de estabilización y ajuste (la seguridad del Canal en Panamá, la derrota del FSLN, la reversión de las revoluciones potenciales en El Salvador y Guatemala, la estabilización de Honduras como plataforma de la intervención, el refuerzo de Costa Rica como escaparate de la democracia y como aliado en la estrategia contra Nicaragua) o perdieron su primacia o se desvanecieron. Paralelamente, el presupuesto dedicado a esos fines también ha desaparecido. Los imperativos políticos y económicos en la arena doméstica estadounidense han cambiado con el triunfalismo de la postguerra fría y del "nuevo orden mundial" de inicios de los años noventa, y con la victoria electoral de Bill Clinton en 1992, generalmente atribuida a la reflexión exitosa del cansancio público con la política exterior, captado en el lema "es la economía, tonto". Además, el discurso ideológico ligado a los Programas de Ajuste Estructural se ha canalizado casi únicamente a través de las ideas neoliberales; la idea de Centroamérica como "el patio trasero",

37. CRIES, “Panamá: situación económica”, en CRIES, Anuario: Centroamérica 93, Managua: CRIES, 1993, pp. 230-240.

38. Ricaurte Soler, La Invasión de Estados unidos a Panamá: neocolonialismo en la posGuerra Fría, México: Siglo Veintiuno, 1991.

39. Entrevista, Panamá, 15 de enero de 1993.

40. Norsworthy, Kent y Barry, Tom, Nicaragua: A Country Guide, 2a ed., Albuquerque: The Resource Center, 1990, p. 38

41. Ver Saldomando, Angel, El Retorno de la Agencia Internacional de Desarrollo; el caso de Nicaragua: condicionalidad y reestructiuración, Managua: CRIES, 1992; Bendaña, Alejandro, Hegemonía y nuevo orden internacional: Estados unidos ante el desafio de Alemania y Japón, Managua: Centro de Estudios Internacionales, 1992. Entrevistas a Oscar Neira, economista, CRIES, Managua, febrero de 1993; Arturo Gallese, director ejecutivo, CRIES, Managua, enero-abril, 1993. 
ha quedado tal vez en el fondo, pero el lenguaje de "seguridad" y "amenazas marxistas" está ahora polílicamente marginado.

\section{Las consecuencias multifacéticas y entrela- zadas de los PAE}

Es un cliché que el ajuste y la reestructuración lienen unos costos sociales y políticos, al punto que el Fondo Monetario Internacional, el Banco Mundial, la Agencia Internacional de Desarrollo, sus respectivas oficiales y publicaciones lo repiten casi diariamente en los noventa. El peso caería desproporcionadamente sobre la mayoría pobre en los países que implementan los Programas de Ajuste Estructural. En Centroamérica, la fracción de la población "bajo la línea de pobreza" va desde aproximadamente el 30 por ciento en Costa Rica y 50 por ciento en Panamá hasta entre 60 y 70 por ciento en Nicaragua, Honduras, Guatemala y El Salvador ${ }^{42}$. La austeridad, los recortes severos a los presupuestos estatales, las devaluaciones, la desregulación y los demás elementos del paquete Programa de Ajuste Estructural, se entendía que empeorarían los niveles de vida para las mayorías. Se reconoce universalmente que altos niveles de pobreza y marginación existían antes del ajuste: "A principios de los ochenta dos tercios de la población centroamericana no cubrían sus necesidades elementales" 43 . Sin embargo, Stein comenta, con base en el consenso de las ciencias sociales centroamericanas, que "todo indica que la situación, lejos de mejorar, se agrava. Ahora tres cuartas partes de la población centroaméricana producen poco o nada, y no consumen nada"44.

La observación crítica de Stein infiere lo obvio: que el ajuste y la reestructuración tienden a marginar a la mayoría y exacerbar la miseria. Las políticas de "compensación social", por ejemplo, los programas de ayuda alimentaria ${ }^{45}$, parecen diseñadas principalmente para mitigar los costos sociales del ajuste y reducir las consecuencias políticas potencialmente muy conflictivas. Pocos analistas insisten en que los previos modelos de desarrollo, entendidos como proyectos nacionales y transnacionales de acumulación, no generaron pobreza y marginación social. Al contrario, lo que los críticos de los Programas de Ajuste Estructural, respecto al ajuste $\mathrm{y}$ la reesiructuración, quieren plantear es que hay una continuidad entre la acumulación preajuste con la acumulación "reestructurada", en particular en lo que respecta a la mayoría, pues el ajuste y los Programas de Ajuste Estructural agudizan la marginación. Dicho sencillamente, la lógica del neoliberalismo inevitablemente crea una población sobrante, gente con poco o ningún papel en el mercado, cuya labor y consumo no son necesarios para el funcionamiento "eficiente" de las economías reestructuradas ${ }^{46}$.

El concepto de "crisis", entonces, se desplaza del campo económico y estatal hacia los pueblos. Si las economías son eficientes "en términos del mercado", los Estados son juzgados como exitosos; en un universo de la iniciativa empresarial y la responsibilidad individual, una "crisis" de po-

42. Para mayor información sobre la pobreza regional en los ochenta, ver Menjívar, Rafael y Trejos, Juan Diego, La Pobreza en América Central, San José: FLACSO, 1990.

43. Stein, Eduardo, "Introducción: hacia la concepción y puesta en marcha de un proyecto alternativo para Centroamérica", en Stein y Arias Peñate, eds., op. cit., p. vii. Ana Hernández, directora de la Casa de la Mujer, dice que "con el deterioro en la salud, la educación y las condiciones del trabajo, y con la expansión del sector informal, 70 por ciento de la población [costarricense] sufre la pobreza de algún nivel". Entrevista, San José, 19 de febrero de 1993.

44. Ibid

45. Ver Garst, Rachel, “Ayuda alimentaria de Estados unidos a Costa Rica”, Documento de análisis No. 13, San José: Centro de Estudios para la acción social, 1990.

46. Hugo Noé Pino, presidente del Colegio Hondureño de Economistas en 1992-93, comentó: "Bajo el ajuste hay un excedente de gente". Entrevista, Tegucigalpa, 13 de noviembre de 1992. 
breza y marginación se convierte en un asunto personal, a lo mejor en un asunto que la "sociedad civil" debe resolver con la caridad y la "autoayuda". Entonces la "crisis" no pertenece al Estado, por lo cual no se debe tratar en la arena de la política pública. Como dijo el teórico social, Helio Gallardo, cuando se refirió tanto a las crisis económicas de los ochenta como a la pobreza, marginación y desintegración social de los noventa en Costa Rica (aunque sus comentarios se podrían extender a todos los países de la región), "éste no es un país de crisis. Hay gente, cierto, que las vive, pero no el país" ${ }^{47}$. Por supuesto, sc manifiestan "Ios costos sociales de los logros del ajuste", según Manuel Acosta Bonilla, miembro del gobierno reformista de los setenta en Honduras y Secretario Ejecutivo de la Comisión Presidencial sobre la Modernización del Estado ${ }^{48}$. Estos costos incluyen un aumento de los sin vivienda, de la delincuencia y de la violencia contra la mujer - en general, en todos los indicadores de la desintegración social ${ }^{4+}$. La seguridad personal y de la propiedad privada, la ejecución judicial, los servicios polićácos y las cárceles se convierten en prioridades sociales y políticos a un grado mayor y se sitúan en los primeros rangos de las agendas políticas nacionales ${ }^{50}$. Es así que la "gobernabilidad" se ha hecho fundamental en las Instituciones Financieras Internacionales, el aparato de política exterior de Estados Unidos, los Estados y gobiernos centroamericanos, las organizaciones no-guhernamentales (ONG's) nacionales e internacionales, los salones empresariales, las universidades y los institutos dedicados a la investigación socioeconómica por toda la región. Ya no es el caso de que la "gobernabilidad" significa solamente democracia formal, un presupuesto balanceado y los pagos de la deuda; ahora quierc decir un "Estado de Derecho", una sociedad civil con un grado de autonomía y un "pacto social" que manticne las condiciones para la acumulación de capitales bajo la recstructuración y que amortigua los efectos sociales más graves.
La marginación en Centroamérica se traduce en la polarización social. El desequilibrio social en cuanto a consumo, necesidades elementales, biones sociales, como la educación y la salud, en los bienes de comodidad se han agudizado con el ajuste y la reestructuración. La reducción severa en los gastos sociales ha dejado a muchas personas sin empleo, y ha orillado a los trabajadores del sector público hacia el sector informal. Quienes previamente producían dentro de una economía de subsistencia individual, familiar o comunal, cada día tienen que adecuarse más a los criterios del mercado, y con frecuencia al no poseer los medios, no pueden competir y se hunden en la mise-

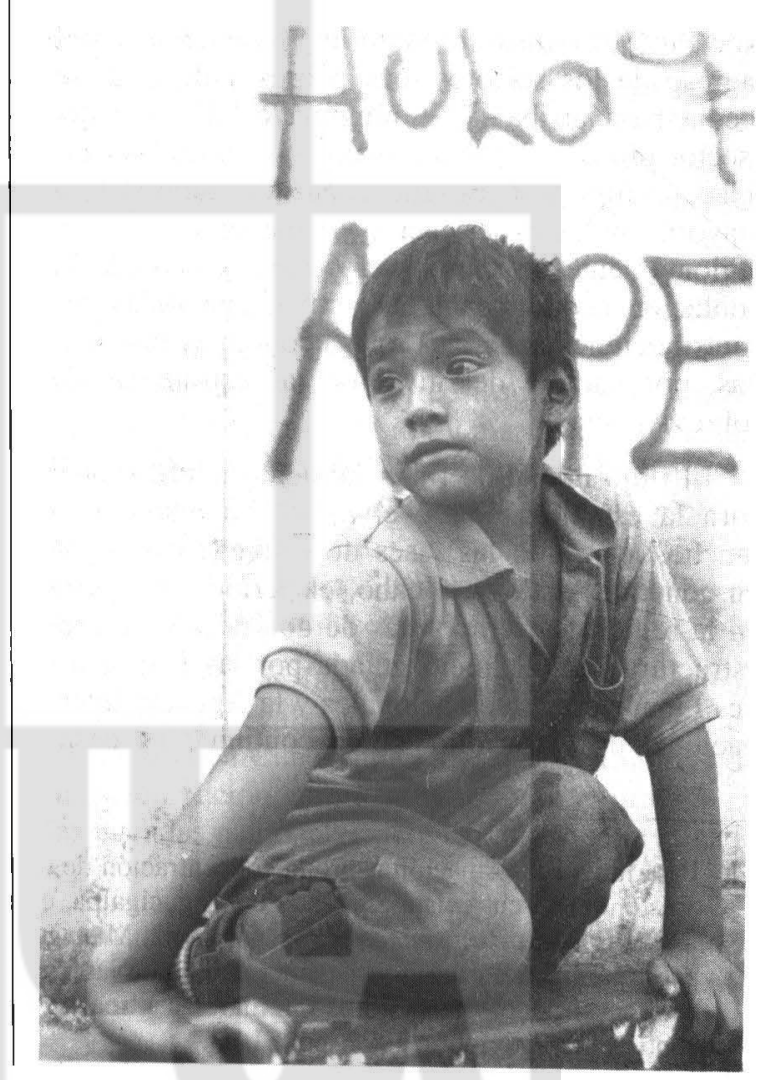

47. Entrevista. Departamento Ecuménico de Investigación. San José, 23 de febrero de 1993.

48. Entrevista. Tegucigalpa. 23 de noviembre de 1992.

49. La frase "patologías sociales" capta la preocupación de los científicos sociales centroamericanos por la desintegración que ocurre bajo los Programas de Ajuste Estructural. Ver Yong Ch., Marlon, "Sinopsis de la patologías sociales en Costa Rica”, en Manuel Villasuso, ed., El nuevo rostro de Costa Rica, Heredia: Centro de Estudios Democráticos de América Latina, 1992, pp. 71-96.

50. Como es el caso en Estados unidos y Canadá, la criminalidad de las pandillas y de la juventud, en general, son temas cotidianos en los medios de comunicación en Centroamérica, mientras los problemas generados por los numerosos soldados. guerrilleros y contras desmovilizados son distintos y están presentes por toda la región. 
ria y la indigencia. Los barrios pobres proliferan aún más rápido que en los años setenta y ochenta. En las sociedades donde las cifras de pobreza, desempleo, desnutrición y otros indicadores de la baja calidad de vida son más altas - Nicaragua, El Salvador, Guatemala y Honduras-, hasta el observador más casual y desinteresado no puede evitar darse cuenta que un 85 por ciento de la población queda exenta de los beneficios de la economía ajustada y reestructurada. La gente simplemente no dispone de los medios necesarios para participar en la cultura de "la producción de valor agregado", el consumo, la libre elección y "la expresión del estilo de vida" a la cual un 15 por ciento de la sociedad tiene aceso. Como expresa Hugo Noé Pino: "el ajuste produjo una transferencia del ingreso de los sectores más pobres y de la clase media para arriba" 51 . Y ninguna celebración del "sector informal" como crisol o vivero de las cualidades empresariales, fue capaz de aumentar la mayoría de las experiencias vividas en ese sector, regionalmente alrededor del 60 por ciento de la población económicamente activa, con todas sus contribuciones concretas a las economías respectivas, por encima del nivel de las estrategias de sobrevivencia ${ }^{52}$.

El flujo inicial de financiamiento internacional para la estabilización y el ajuste ha disminuido mucho, así como las fases de la reestructuración en general. Al fin y al cabo, el período de ajuste en la región ha durado más de una década. La reestructuración, al inicio guiada por las Instituciones Financieras Internacionales y la Agencia Internacional de Desarrollo, debía continuar su desa- rrollo de acuerdo con las dinámicas del mercado. Y así ha sucedido en alguna medida: la exportación no-tradicional, aunque todavía está subsidiada, ha aumentado pero aún no ha llegado a los niveles originalmente esperados. En los casos más exitosos - en Costa Rica, Guatemala y Honduras-, la proporción no-tradicional del total de exportación no ha superado el 15 por ciento, ni ha crecido a unas tasas altas y sostenidas. Las exportaciones no-tradicionales no han podido desplazar la dependencia de las economías regionales en los productos de agroexportación tradicional: el café, el banano, la carne y el algodón.

La liberalización de precios de productos agrícolas para el consumo doméstico ha creado ganadores en el mercado, pero tienden a ser quienes ya eran productores mayores y más capitalizados ${ }^{53}$. El esparcimiento y la eliminación de las tarifas y las restricciones en la importación han situado a los productores más pequeños bajo la presión competitiva de la importación: los pollos congelados de Arkansas se compran más baratos en los supermercados de Managua que el producto local de la carretera de Masaya; los productos alimentarios básicos norteamericanos (por ejemplo, el aceite, el jabón y hasta el frijol en lata) inundan las tiendas en Guatemala. La ayuda alimentaria internacional, que proviene principalmente de la Agencia Internacional de Desarrollo, y los precios bajos que se pagan a los productores de los granos básicos (maíz, frijol, arroz) actúan como desincentivos para los productores locales; mientras que los criterios de crédito dictados por el mercado financiero suelen favorecer a los productores mayo-

51. Para mayor información sobre la concentración de la riqueza en cada país centroamericano durante la crisis y el ajuste, ver la entrevista realizada en Tegucigalpa, el 13 de noviembre de 1992. Vea el reportaje especial "Los nuevos ricos", Pensamiento Propio, No. 92, Managua: CRIES, julio, 1992, pp. 17-31. Para obtener informacion sobre la diversificación y reestructuración de las viejas oligarquías, ver también Casasu Arzú, Marta Elena, "El retorno al poder de las élites familiares centroamericanas 1979-1900”, Polérica, No. 18, San José: FLACSO, septiembre-diciembre, 1992, pp. 51-63.

52. Ver la discusión informada e informativa sobre el sector informal por Lionel Méndez d'Avila, "Visión, términos y perspectivas de la informalidad en el Istmo Centroamericano", en Stein y Arias Peñate, eds., op. cit., pp. 453-511.

53. Efectivamente se pueden citar ejemplos de pequeños productores que logran una transición eficaz a la producción no-tradicional, de la cual obtienen ganancias elevadas. El historiador Manuel Solís, director del Instituto de Investigaciones Sociales de la Universidad de Costa Rica, señala a su pueblo natalicio Zarcero, donde muchos ex cafetaleros ahora venden flores ornamentales a clientes en Nueva York, Amsterdam y Miami (Entrevista, San José, 24 de febrero de 1993). Al mismo tiempo, Don Raudelio, agricultor en un pueblo no muy lejos de Zarcero y un dirigente de UPANACIONAL, uná organización de productores pequeños y medianos, dice: "hemos vivido el ajuste desde 1978 y todo ha sido un deterioro desde entonces" (Entrevista, San José, 19 de febrero de 1993). 
res, más eficientes y más rentables. Para una gran cantidad de productores agrícolas centroamericanos, el ajuste y la reestructuración no se limitan a desbaratarlos, sino que más bien los eliminan ${ }^{54}$. La producción y los "espacios" disponibles en el mercado dentro del ajuste y la reestructuración son limitados y desiguales. Es como si la reestructuración constituyera una nueva demarcación de la "población sobrante"; la orientación al mercado externo no sólo desplaza la producción exportadora no rentable, sino también la producción para el consumo doméstico. En el punto más cruel, la reestructuración borra la categoría marxista de "trabajo socialmente necesario" por la del "trabajo acumulativamente necesario", y denomina a la mayor parte del trabajo en las economías centroamericanas como "innecesario".

La estabilización de la moneda, la orientación del capital privado hacia la especulación, la circulación, el comercio, los servicios y el consumo lujoso se han constituido en una inversión privada nacional mucho más baja de lo que el pensamiento neoliberal proyectaba como resultado de la liberalización, privatización y renegociación de la deuda externa ${ }^{55}$. En la inversión productiva limitada de Centroamérica, la meta general dirigida a reestructurar la diversificación alterna con énfasis en las variables de nuevos productos para la exportación (el camarón, el brócoli, las flores) y en las maquiladoras, a veces se acompaña de un "culto de cargo", una fantasía de que el gran capital extranjero va a invertir sumas astronómicas" 5 . Mucho "capital expatriado" que ha regresado a la región se ha dirigido al comercio, a los servicios y al sector banquero privado, con lo que ha descuidado y no ha permitido la inversión productiva. Los centenares de millones, hasta miles de millones de dóla- res, remitidos por centroamericanos que viven $y$ trabajan en Estados unidos, son considerados por economistas de diversa adscripción ideológica, especialmente en El Salvador, como un capital potencial para inversiones, pero son recursos muy difíciles de captar y canalizar ${ }^{57}$. Otras fuentes de capital que los teóricos neoliberales rara vez consideran, pero que sí tienen presencia y peso, incluyen los "narcodólares" y los recursos financieros y materiales controlados por las instituciones militares centroamericanas $^{58}$. Sin embargo, parece que esos capitales manifiestan la misma conducta de los más ortodoxos, o sea, que no llenan las expectativas óptimas para las economías ajustadas y reestructuradas.

Actualmente, con diez o quince años del régimen de Programas de Ajuste Estructural, no se puede afirmar que la reestructuración haya consolidado un nuevo modelo de desarrollo, ni los ejes definidos de la acumulación que reemplazarán a los viejos, ni el agroexportador, ni el capitalismo del "welfare state" (estado de bienestar) ni la industrialización por la sustitución de la importación, ni el modelo de la industrialización regional (Mercado Común Centroamericano). No se puede negar que existe un proceso de reestructuración caracterizado más por la exclusión y marginación que por la inclusión y la movilidad social ascendente. El proceso se impulsa más por las fuerzas globalizantes del mercado, que por unas agendas nacionales determinadas por la sociedad civil local y su propia variedad de necesidades sociales.

Tal como las fuerzas del mercado global han cambiado y devaluado los papeles productivos de la mayoría en Centroamérica, así la centralidad de la estabilización, el ajuste y la reestructuración en las agendas nacionales han cambiado y devaluado

54. Para un análisis general, ver Baumeister, Eduardo, "Características y potencial de la agricultura en la estrategia alternativa", en Stein y Arias Peñate, eds., op. cit., pp. 349-399. Para una discusión sobre la experiencia costarricense, ver Román, Isabel, "Efectos del ajuste estructural en el agro costarricense", Polémica, No. 19. San José: FLACSO, enero-abril, 1992, pp.13-25.

55. Clara Arenas, directora de AVANCSO, manifiesta que: "el único sector dinámico de la economía guatemalteca [en los 90] es el sector financiero", entrevista, Guatemala, 2 de abril de 1993.

56. En Nicaragua se ciclan y reciclan rumores que unas transnacionales japonesas financieran un "nuevo canal", incluso hasta que se van a usar explosiones nucleares para cavarlo. Se escuchan frecuentamente los términos "otro Taiwan" y "los NIC's [Países Recientemente Industrializados] de los 90" por los medios de comunicación y en las cámaras de comercio de todo el istmo.

57. Entrevista a Javier Castillo de la Comisión para la Reconstrucción y el Desarrollo del FMLN, San Salvador, 19 de marzo de 1993.

58. Un artículo sobre el narcotráfico y su influencia económica y política en la región, "El narco nos domina", Pensamiento Propio, No. 91, Managua: CRIES, 1992. 
las funciones de los distintos Estados. Bajo las condiciones de la Guerra Fría y la hegemonía contrarrevolucionaria, desde la contrainsurgencia y los "estados de la seguridad nacional" en los sesenta hasta los contras, los Estados de la región primariamente se definieron en referencia a sus funciones represivas. Al mismo tiempo, eran "instrumentalistas" y "regulacionistas", si no intervencionistas, en los regímenes de acumulación y en los modelos de desarrollo. En ambas esferas - la seguridad nacional y la acumulación- el poder hegemónico ejercía una presencia, y en los casos extremos existía casi una situación de "poder dual" o de "gobierno paralelo"59. Se podría concluir que los Estados centroamericanos ejercían solamente una soberanía mediatizada y se apoyaban en una autoridad y legitimidad dependientes.

Desde lo que podría llamarse régimen transnacional del ajuste estructural para las sociedades capitalistas dependientes de la periferia (si tal lenguaje fuera de moda), la autoridad, legitimidad y poder de los Estados en Centroamérica se han vuelto al mismo tiempo más dependientes y más difusos. Las Instituciones Financieras Internacionales, que dominan el campo de la planificación, el fïnanciamiento y la administración internacional del régimen ajuste-reestructuración (dejando de lado por ahora la función del capital transnacional empresarial), han ocupado el espacio cedido por los Estados. La Agencia Internacional de Desarrollo ha sido la institución de mayor influencia. Una serie de estudios ${ }^{60}$ se han publicado por una red de investigadores e institutos centroamericanos; en ellos se documenta la penetración del discurso neoliberal de la Agencia Internacional de Desarrollo en relación con la concepción, financiamiento y administración de los Programas de Ajuste Estructural. Hasta un 35 por ciento del presupuesto estatal en Costa Rica durante los ochenta, y más en El Salvador cuando se le agrega la ayuda militar, y proporciones significativas para el resto de los países centroamericanos en los noventa, han provenido de los programas de la Agencia Internacional de Desarrollo. En cada país centroamericano existe cierto grado de un cogobierno, con una estructura de asesores de la Agencia Internacional de Desarrollo, que trabajan estrechamente con ministerios y agencias públicas en las esferas de la política fiscal, monetaria y social relevantes a las agendas del ajuste y reestructuración ${ }^{61}$.

Además, el Fondo Monetario Internacional, el Banco Mundial, otras Instituciones Financieras Internacionales y agencias internacionales de desarrollo económico colectivamente avanzan en las agendas de los Programas de Ajuste Estructural y mantienen equipos técnicos y asesores en los países; asimismo ejercen influencia en ministerios y agencias nacionales. Cuando esta presencia transnacional y de la Agencia Internacional de Desarrollo se suman a las misiones de la ONU y la OEA, que supervisaron los acuerdos y procesos de paz en los años 1989-1994, especialmente en El Salvador y Nicaragua, y a las actividades de los organismos no gubernamentales internacionales que trabajan en las arenas de la compensación social y los servicios sociales, resulta un estilo de gobernabilidad compartida y transnacionalizada ${ }^{62}$. El Estado se ha compactado en Centroamérica; la soberanía formal se mantiene, pero la soberanía, en la realidad práctica, está truncada y es difusa.

\section{La ciencia social, la izquierda y los movimien- tos populares: los límites de respuesta a la agenda ajuste}

Las dimensiones políticas de las crisis en Centroamérica en los setenta y ochenta incluyeron la de los discursos ideológicos dominantes. Su hegemonía se debilitó mientras las alternativas - una

59. Los casos de "poder dual" en la seguridad nacional en El Salvador y Guatemala son ampliamente documentados por McClintock, Michael, The American Connection. State Terror and Popular Resistance in El Salvador, London: Zed Press, 1985; y McClintock, The American Connection. State Terror and Popular Resistance in Guatemala, London: Zed Press, 1985.

60. La mayoría de estos estudios han sido citados en las notas previas; fueron coordinados por CRIES con base en la información de Managua.

61. Este hecho se cita con frecuencia en los comentarios de las ciencias sociales centroamericanas, y era repetido por Robert Carty, periodista canadiense y director del Instituto de Estudios Centroamericanos en San José; entrevista 24 del febrero de 1993.

62. David Holiday, director de Americas Watch en El Salvador, especificó esta conclusión con respecto a las funciones de ONUSAL, el aparato de la ONU que supervisaba el proceso de paz en El Salvador. Entrevista, San Salvador, 18 de marzo de 1993. 
teología radicalizada de liberación, las mitologías populares revolucionarias, la teoría económica socialista, el nacionalismo antiimperialista y la solidaridad latinoamericana- recuperaron y crearon espacios para proyectos populares mayoritarios de democracia, identidad, modernidad y desarrollo. El conjunto de estos proyectos se llamó "la lógica de la mayoría" y se expresó más cabalmente desde una situación de poder estatal con los sandinistas en Nicaragua, y desde una situación de "poder dual" con el FMLN en El Salvador.

Ese conjunto de alternativas, que se formaba en un discurso ideológico contrahegemónico, fue en su momento enfrentado por una ofensiva tripartita. La ofensiva encontró su glosario y carácler en el lenguaje del equipo de Reagan que fue responsable del "patio trasero", es decir, Centroamérica. El anticomunismo era el elemento más plano de la campaña; Nicaragua fuc pintada como "un Estado totalitario terrorista" y punta de lanza para los planes subversivos cubanos y soviéticos para el hemisferio. Había una lista larga de objetivos que se esperaban lograr con el despliegue del anticomunismo. El segundo elemento en la ofensiva fue el programa amplio de una contrarrevolución; esto quería decir revertir las amenazas a la propiedad capitalista, en general, y específicamente a las empresas privadas más valiosas, fueran éstas inversiones transnacionales o de las "oligarquías" locales; y tildar la democracia participativa de caos, "turbas" o manipulación cínica de la vanguardia estalinista. Este esfuerzo fue diseñado para recuperar el terreno de la "democracia". La izquierda revolucionaria y los movimientos populares, tantos los tradicionales como los "nuevos" y helerodoxos, habían avanzado mucho en ese terreno, lo redifinieron, agregaron y cambiaron a la lista de actores legítimos en el mismo, y exploraron distintas prácticas políticas.

En último término, los dos elementos, el anticomunismo y la democracia contrarrevolucionaria, ocuparon un segundo lugar en la ofensiva. Fue el Ienguaje del "mercado libre", el discurso del neoliberalismo, el que más logros obtuvo en la batalla ideológica. Este discurso, el tercer elemento, pudo integrar los distintos aspectos de la ofensiva: la

erdadera democracia sería solamente el producto de la función desenfrenada del mercado; el Estado y todos sus instrumentos de la polílica pública que regían en los campos de la planificación, la producción y la distribución, se tendrian que suprimir; la cconomía socialista y la élica comunista eran fundamentalmente erradas, basadas en premisas de teoría social falsas (a lo mejor bien intencionadas pero que reflejaban la envidia y la duda sobre el éxito material individual, y lo peor fue que se convirtieron en ataques contra las leyes naturales y la libertad personal; una lógica diabólica de dictadura). El tiro de gracia vino con el colapso de la Unión Soviética y la desaparición de la mayoría de gobiernos formalmente socialistas. Se había ganado la Gucrra Fría y no solamente como una contienda entre las superpotencias, con todas sus pertenencias físicas, sino también como un juicio práctico, divino y final sobre los dos sistemas en su totalidad, en sus dimensiones sociales, económicas y políticas. Las frases "Fin de la Guerra Fría", "Fin de la Historia" y "Nuevo Orden Mundial" expresaron el triunfalismo y la exaltación que acompañaron tal desenlace del orden postguerra mundial.

Como ideología hegemonizante, el neoliberalismo ha sido extraordinariamente exitoso: "Con la política neoliberal de las décadas de los setenta y los ochenta de este siglo, vuelve a surgir en el mundo del siglo $\mathrm{XX}$ un nuevo y todopoderoso utopismo"63. Ello promete todo: la libertad personal y el valor individual, la oportunidad ilimilada vía la competición en el mercado, tanto para los individuos como para los países, la igualdad ante las

63. Hinkelammert, Franz, "La lógica...", p. 3. 
leyes de ese mercado, el encaje "natural" entre la "naturaleza humana" y la organización socioeconómica y la ecuación de la democracia política con la función del mercado capitalista. Hay muchas críticas hacia el neoliberalismo en Centroamérica ${ }^{64}$, que generalmente se centran sobre las contradicciones teóricas, o que señalan la lógica totalizante y excluyente, pero ninguno de los cien entrevistados -entre economistas, sociólogos, politólogos e historiadores, entre octubre de 1992 y abril de 1993- negó que el neoliberalismo hubiese puesto en jaque a los demás contendientes ideológicos. La agenda económica neoliberal se ha incorporado, generalmente, desde la derecha hasta la izquierda, y la conducta social refleja el impacto del neoliberalismo: en palabras de una extranjera residente por muchos años en Managua, simpatizante de la revolución sandinista, "ahora en Nicaragua se cobran hasta las sonrisas". Para muchos movimientos populares, por ejemplo, las cooperativas campesinas atendidas por los organismos no gubernamentales internacionales y nacionales, "el incremento de poder" se traduce en "estrategias de viabilidad mercantil" y en "el logro de eficiencia productiva".

Hasta la fecha ni la izquierda radical ni los partidos políticos, ni los sindicatos y otras organizaciones populares, ni los institutos de investigación han planteado una alternativa efectiva a la agenda neoliberal de ajuste. De hecho, se han sentido el cnojo y el rechazo; surgieron manifestaciones y protestas populares en los ochenta y los noventa en Costa Rica, en 1990-91 en Guatemala, y sonaron rálagas de protesta en Honduras, Nicaragua, El Salvador y Panamá. Consecuencias políticas mayores sc pueden atribuir al descontento popular con el ajuste. Cuando los Sandinistas comenzaron a implementar las políticas de ajuste estructural en
1986-87, fueron avisados por sus asesores económicos del costo político, y seguramente la reducción del apoyo popular se registró en la derrota electoral de 1990. En las elecciones de 1993-94 en Honduras, Costa Rica y Panamá, la estrategia política consciente de los-partidos mayores de oposición fue identificar al partido gobernante como el "duro" en la aplicación del ajuste para presentarse ellos como los más "humanos". En los tres casos, la oposición ganó la elección, no obstante la falta de una plataforma clara de rechazo del ajuste, así como un programa elaborado de alternativas. Los movimientos populares han mostrado una resistencia enérgica ante el impacto social del ajuste; en algunos países y momentos han logrado mitigar los efectos más dañinos ${ }^{65}$. Sin embargo, en ningún país han podido invertir los Programas de Ajuste Estructural ni desarrollar alternativas viables que abarquen a la mayoría de la población ${ }^{66}$. Existen propuestas específicas a ciertos sectores económicos, pero éstas no representan agendas nacionales alternativas, sino "ajuste al ajuste". La Agencia Internacional de Desarrollo y el Fondo Monetario Internacional han incorporado tal lenguaje y su literatura habla de "proteger" las necesidades básicas de la mujer, de los más pobres, de las etnias marginadas, de los grupos indígenas, etc.

Las organizaciones populares, los intelectuales e investigadores que durante los sesenta, setenta y ochenta expresaron un compromiso con "la lógica de la mayoría" inicialmente rechazaron toda la estructura intelectual del ajuste. Con el tiempo, muchos han aceptado el diagnóstico neoliberal de las crisis económicas. Otros, de mala gana han aceptado las premisas neoliberales que tratan "la naturaleza del ser humano", mientras siguen en disputa acalorada con las recetas de los Programas de

64. Ver "Las Incoherencias del proyecto neoliberal impuesto a la región", Envio, No. 112-113, Managua: Universidad Centroamericana, marzo, 1991.

65. Carlos Arita, historiador e investigador a $\mathrm{CEDOH}$, considera que el movimiento popular hondureño tuvo el mayor éxito en la región en embotar el impacto social de los Programas de Ajuste Estructural. Entrevista, Tegucigalpa, 5-6 de enero de 1993. En Nicaragua, la derrota electoral de los sandinistas en 1990 "liberó" en cierta medida a los movimientos agrarios y sindicales, mayormente afiliados a los sandinistas y relativamente reposados, mientras el gobierno sandinista aplicaba una clase de Programas de Ajuste Estructural en los ochenta. En Nicaragua, en 1990 y 1991, estos movimientos participaban en las huelgas y protestas callejeras contra los cortes del sector público, los despidos masivos, la privatización y los reveses en la reforma agraria bajo el nuevo gobierno de Violeta Chamorro.

66. Ver "Protesta mal enfocada e inmadurez en la concertación económica", Envio, No. 112, Managua: Universidad Centroamericana, marzo, 1991, pp. 23-33. 
Ajuste Estructural y con los resultados teóricos ${ }^{67}$. Una ironía notable es que investigadores con un compromiso histórico hacia los sectores populares se encuentran ubicados en la defensa de los Estados, los gobiernos y las políticas sociales que anteriormente atacaron y tildaron de "reformismo burgués" (como en Costa Rica y Panamá). También han tenido que enfrentar la debilidad histórica de la izquierda en teorizar un proyecto de acumulación. Históricamente, el enfoque de la teorización izquierdista y de las organizaciones populares ha sido la redistribución radical y la nacionalización, tanto de la propiedad como de la producción. Todos los problemas teóricos y prácticos —de la planificación central, la productividad y eficiencia socialista en un mercado global capitalista, o de los sectores públicos endeudados en las economías mixtas de la región, desde Guatemala y Nicaragua hasta Panamáhan sido agudizados por el colapso de la Unión Soviética y por cl aparente callejón sin salida de la teoría económica socialista. Tampoco hay una "división socialista internacional del trabajo", el CAME de las economías socialistas, ni la relación cconómica cubanosoviética que anteriormente, por lo menos, ofrecía un marco institucional para los países que optaban por un camino de desarrollo socialista.

Entonces se sigue la búsqueda permanente que ha caracterizado al proyecto de las élites regionales desde la independencia; se buscan modelos de desarrollo, las mercancias rentables y perfectas y fuentes ilimitadas de inversión extranjera. El esfuerzo ahora se hace en un mercado globalizante y totalizante: el mercado lo es todo y todo se privatiza ${ }^{68}$. El discurso de la reestructuración a la vez amenaza y promete: si no te ajustas y no te reestructuras, estás perdido; debes ser competitivo o te aplastarán; puedes salir victorioso, si te conformas a lo siguiente... Pero si todos los países pueden ser, y tienen que ser competitivos, ¿no quiere decir que de todas maneras, no todos pueden ser ganadores? ¿Cuántos países productores de brócoli para la exportación "no-tradicional" pueden haber a la vez? ¿Cuántos podrán identi-

ficar y ocupar "nichos" especializados en el mercado de agroexportación? Todos quieren convertirse en un NIC (Nuevos Países Industrializados), pero, ¿todos pueden atraer inversión maquiladora al mismo tiempo? ¿Cómo asegurar la combinación precisa de políticas públicas y "ventajas comparativas" que garantizarán una inversión significativa de las compañías transnacionales? No plantear esas interrogantes implica la amenaza oscura de un retraso y una marginalización permanentes, es decir, nunca llegar a la verdadera modernidad ni mucho menos disfrutar de las emanaciones culturales del mundo postmoderno. Estas consideraciones y temores forman una disciplina estricta y, por eso acaso, no hay que sorprenderse de que los discursos de respuesta a los Programas de Ajuste Estructural y a la hegemonía del neoliberalismo tiendan a "las alternativas dentro del ajuste", a "los espacios" y a la "inserción" de la mayoría marginada, del sector informal y de los "nuevos" sujetos sociales dentro de un orden reestructurado de la producción y comercialización.

6. Los elementos primarios de las agendas nacionales centroamericanas en el contexto del ajuste económico y la reestructuración democrática

El paradigma de la economía política generalmente abarca el estudio del nexo de las dimensio-

67. Fue típica la entrevista con Silvia Lara, directora ejecutiva del Centro de Estudios para la Acción Social (CEPAS), San José, 15 de febrero de 1993; trazaba la trayectoria de CEPAS por el sendero común. Actualmente. como instituto de investigación y capacitación dedicado al avance de los sectores y organizaciones populares, responde a pedidos con estudios y talleres sobre "la inserción al mercado reestructurado y globalizante".

68. Para una teorización de la "globalización" y la "totalización", ver Hinkelammert, op. cit. 
nes políticas y económicas en una sociedad. Ahora, en Centroamérica, ese paradigma o disciplina en las ciencias sociales se enfrenta con una asimetría, un desencaje entre un régimen ajustado y reestructurado de acumulación capitalista y una democratización/ampliación de la ciudadanía. El título de un libro reciente dedicado a "las alternativas desarrollistas en el istmo centroamericano", Democracia sin pobreza ${ }^{69}$, capta las dos dimensiones de las agendas regionales en los noventa y para el siglo venidero. La tarea histórica de adelantar y profundizar la democratización de las sociedades centroamericanas acompaña la liberalización de las economías, con todas las dinámicas y consecuencias concretas que implican esos dos procesos. En palabras de Edelberto Torres-Rivas, "en la presente década de los noventa, la tarea intelectual y política parece ser la democracia... pero también lo es entrentar con la óptica que le corresponde, la crisis económica"70. Esa agenda manifiesta una tensión clásica en la teoría política. la de la democracia política, con su igualdad inmplícita en el terreno de la ciudadanía y contrapuesta a la desigualdad cconómica y su resultado lógico, la incquidad social. Los crílicos de la democracia liberal se han concentrado en esá tensión y sostienen que en ausencia de democracia económica, cualquicra que sea la delinición, la democracia política permanece hueca, falsa, a lo mejor incompleta; de ahí su cnforuc en "la justicia social" y el papel del Estado en corregir el desequilibrio

\section{La democracia en Centroamérica}

\subsection{Elecciones}

En cl contexto del ajuste y la reestructuración, la democratización centroamericana presenta va- rios aspectos notables. Primero, las elecciones formales durante los noventa han llevado al poder a gobiernos comprometidos con las agendas de los Programas de Ajuste Estructural. Asimismo, los Estados se han restructurado conforme a los Programas de Ajuste Estructural; el proceso ha dejado a entidades, previamente descritas como "Estados débiles", con opciones mucho más limitadas en el campo de la política pública, especialmente en lo que se refiere al régimen de acumulación y a la distribución de la riqueza social producida bajo ese régimen ${ }^{71}$. Tales Estados, según muchos investigadores de la región, son vulnerables precisamente por la democratización formal y electoral. Con una capacidad reducida para definir y aplicar la justicia social, ven socavada su autoridad y legitimidad también reducidas. En esas circunstancias, asumida a la fragilidad general de los partidos políticos y de las instituciones parlamentarias centroamericanas, se puede pensar en un "desencanto democrático" popular ${ }^{72}$. $\mathrm{Y}$ en este ambiente aumentan las posibilidades de un nuevo militarismo dictatorial, de gobiernos autoritarios populistas, de partidos políticos fragmentados, de altos niveles de abstencionismo electoral y de parálisis institucional. Actualmente, pocos analistas entrevistados o que han publicado sus ideas, consideran que el desencanto democrático mayoritario pudiera dar luz a movimientos revolucionarios renovados ${ }^{73}$. De la izquierda, en su configuración presente, el enfoque está en la "revolución democrática", por ejemplo en El Salvador, y en la expansión de la participación de los sectores populares en las economías ajustadas y reestructuradas de la región. Sin embargo, sc advierte que "la concentración de la riqueza y las decisiones macroeconómicas en las manos de un sector minoritario, en función de su propia ganan-

69. Stcin y Arias Peñate, eds., op. cit.

70. Torres-Rivas, Edelberto, El Tamaño de nuestra democracia, San Salvador: Istmo Editores, 1992, p. 135.

71. Ver Hinkclammert, Franz, "Las tareas futuras...", op. cit., que ofrece una discusión teórica sobre la debilidad histórica de los Estados centroamericanos.

72. La expresión viene de Rodolfo Cerdas, El Desencanto democrático; crisis de partidos y transición democrática en Centroamérica y Panamá, San José: Red Editorial Iberoamericana Centroamericana, 1993.

73. Ver las consideraciones de Rafael Guido Béjar, op. cit. 
cia máxima, provoca la exacerbación de las luchas populares"74.

\subsection{La legalidad}

Segundo, existe un consenso entre los investigadores de las ciencias sociales de la región que la democratización formal, arraigada en todos los acuerdos de paz auspiciados a nivel regional e internacionalmente, debe ser sostenida por un "Estado de Derecho". Este debe concebirse tanto como condición, por ejemplo, que haya leyes y los medios para hacerlas respetar, que se garantice la seguridad pública necesaria para el funcionamiento de las instituciones políticas y del pluralismo político, como aparato estatal con suficiente poder y legitimidad para asegurar esa condición ${ }^{75}$. El Estado de Derecho era la meta de las fuerzas políticas marginadas de la política formal por la represión de los setenta y ochenta en El Salvador, Honduras y Guatemala. Lograr un Estado de Derecho implica desde reformas arrebatadoras hasta la depuración de las instituciones y personal judicial, policíaco y militar involucrado en las violaciones masivas a los derechos humanos en esas décadas.

La dificultad para implementar el Estado de Derecho se manifestó en el rechazo de gran parte de la profesión jurídicolegal, de las estructuras de mando militar y de la policía en El Salvador, del documento de la Comisión de la Verdad-ONU (1993), que subrayó la necesidad de hacer reformas profundas en las instituciones nombradas. La misma renuencia institucional incidió en el progreso lento de la negociaciones entre la URNG, el gobierno y el mando militar en Guatemala ${ }^{76}$. Por otro lado, es evidente que los sectores empresariales con interés en los procesos de reestructuración económica, específicamente en los regionales y transnacionales, deseaban tener vigente un Estado de Derecho. Esto constituiría una parte integral de las condiciones para el comercio, la inversión y la acumulación que querían consolidar y extender.
Así que los sectores empresariales se unieron a lo» sectores populares, los medios de comunicaclón y los partidos políticos para resistir y derrotar ol autogolpe del Presidente Elías Serrano en Guatomala, en 1993. En Honduras, mientra tanto, los grupos empresariales más dinámicos mantuvieron en los noventa una campaña contra la autonomía e impunidad militar.

\subsection{La desmilitarización}

Tercero, aunque las circunstancias y las dinámicas varíen ampliamente en los países de la región, la desmilitarización de las respectivas sociedades fue un requisito fundamental para la democratización ${ }^{77}$. Fue obvio en los casos de Guatemala, El Salvador y Nicaragua, donde la guerras civiles y/o la intervención externa azotaron a las sociedades durante los ochenta. La militarización también afectó a la sociedad y la vida política en Honduras, Panamá y Costa Rica. La cantidad abrumadora de armas y el número de personal uniformado, especialmente los centenares de miles de jóvenes armados en la región, no sólo militarizaron los valores políticos y las formas de organización de la vida política; también canalizaron altas proporciones de los presupuestos y recursos nacionales para uso militar, desangrando a grandes esferas de las economías centroamericanas. Con la disminución de las respectivas instituciones militares, en condiciones de paz negociada y del ajuste, la mayoría de los desmovilizados han sido orillados hacia el sector informal, el desempleo y el devaluado "ejército reserva de fuerza laboral". Muchos se han dedicado a la delincuencia, con lo cual se han sumado a las dinámicas de la desintegración social. A nivel de mando, los militares se han empeñado en articular misiones de postguerra fría que justifiquen presupuesto, estatus e influencia continuos: el combate al terrorismo, el control del narcotráfico, incluṣo hasta la protección ambiental $^{78}$.

74. Medrano, Juan Ramón, "Revolución democrática. Tesis para la estrategia del FMLN", Estudios Centroamericanos, ECA, No. 527, San Salvador: Universidad Centroamericana "José Simeón Cañas, UCA, septiembre, 1992, pp. 730 .

75. Entrevista a Rubén Zamora, Vicepresidente de la Asamblea Nacional, San Salvador, 23 de marzo de 1993.

76. Ver Aguilera, Gabriel, "Camino de paz, camino de guerra. La negociación en Guatemala"; Aguilera, et al., Los Problemas de la democracia, Guatemala: FLACSO, 1992, pp. 73-106.

77. Una expresión elocuente de esta posición se encuentra en Breni Cuenca, "Civiles y militares: una nueva rẻlación?, Tendencias, No. 24, San Salvador, octubre, 1993, pp. 21-23.

78. CRIES, Anuario Centroamerica '94, Managua, 1994, p. 26. 
Como producto de la contracción del Estado hajo el ajuste, del corte severo de la asistencia estadounidense a los militares regionales y de la reducida necesidad de las funciones represivas y de seguridad, las instituciones centroamericanas han tenido que desarrollar un alto grado de "autofinanciamiento". Desde que se establecieron como sectores capitalistas de peso, las instituciones militares guatemaltecas y panameñas se ven imitadas en Honduras, El Salvador y hasta en Nicaragua. En Honduras, por ejemplo, con la privatización bajo los Programas de Ajuste Estructural, el Instituto de Promoción Militar ha presentado ofertas para la compra de la Compañía Nacional de Energía, la empresa cementera y el aeropuerto de Tegucigalpa, más otras propiedades del Estado. Periodistas y analistas, ni hablar de los sectores empresariales inconformes con la presencia militar en el sector privado, frecuentemente documentan esa actividad $^{79}$. Además, tanto en la región como afuera, en Europa y en América del Norte, con regularidad se publica evidencia del involucramiento militar en el narcotráfico.

Pero si un grado de militarización social todavía ejerce influencia en Centroamérica e impacta de manera negativa sobre los procesos para alcanzar la paz negociada y un Estado de Derecho, su persistencia también obedece a la debilidad y la desigualdad en la democratización de las culturas políticas regionales ${ }^{80}$. El sociólogo hondureño, Mario Posas, entre muchos analistas que tratan el tema de la democratización en los noventa, considera que una tradición de responsabilidad civil débil, más la experiencia limitada de la democracia participativa en

Honduras, deja espacio a los militares para continuar con el proyecto de dominación, que es un proyecto con una historia de casi cuatro décadas ${ }^{81}$. Víctor Meza, durante muchos años observador y analista de la institución militar en Honduras, señala la falta de voluntad política que caracteriza a los partidos políticos mayores y a los sectores empresariales. Estos, sostiene Meza, no han aprovechado los espacios abiertos por el fin de la Guerra Fría y el repliegue estratégico de Estados Unidos: "Aquí hay un problema - la tradición mental de cobardía cívica" 82 . Los analistas expresan, por toda la región, su preocupación por el estancamiento del discurso y de la práctica de la democratización. A los procesos formales les falta un contenido popular y mayoritario, esto los vuelve menos capaces para enfrentar las respectivas militarizaciones atrincheradas.

Como producto de la contracción del Estado bajo el ajuste, del corte severo de la asistencia estadounidense a los militares regionales y de la reducida necesidad de las funciones represivas y de seguridad, las instituciones centroamericanas han tenido que desarrollar un alto grado de "autofinanciamiento".
7.4. Las dinámicas de las sociedades civiles incipientes y fragmentadas de Centroamérica

Un cuarto elemento de las agendas de democratización lo constituyen la creación y el fortalecimiento de una cultura política democráti$\mathrm{ca}$, que comprenden facetas y dinámicas disparejas pero a la vez entrelazadas. Como se ha señalado, muchos teóricos centroamericanos proponen que una cultura democrática es un proceso de desenvolvimiento basado en la autonomía y el sentido de responsabilidad de la sociedad civil. La idea de sociedad civil, "una noción de Antonio Gramsci ni bien entendida ni muy desarrollada", en palabras de Edelberto Torres-Rivas ${ }^{83}$, se refiere a sectores sociales organizados que ejercen una función activa, tanto en las múltiples actividades cotidianas y

79. Vea las notas breves en el Anuario Centroamérica '93, pp. 48-53 y el del '94, pp. 26-29. Entrevistas a Manuel Torres, periodista de la Agencia Centroamericana de Noticias, EFE (España) y Pensamiento Propio, Tegucigalpa, 10 de noviembre de 1992; Yazmín Ross, periodista de Panorama, Pensamiento Propio. San José, 22 de febrero de 1993; Gabriel Aguilera, director, FLACSO, Guatemala, 31 de marzo de 1993.

80. Tales criterios son compartidos por algunos oficiales, incluso jubilados, como es el caso del personal afiliado con el centro militar de investigación social, ESTNA, en Guatemala. Entrevistas a Edgar Ponce, director, ESTNA, Guatemala 20 Abril 1993 y Coronel (ret.) Jorge Aparicio Granados, Guatemala, 19 de abril de 1993.

81. Entrevista a Mario Posas, Tegucigalpa, 9 de noviembre de 1992.

82. Entrevista a Víctor Meza, director Centro de Documentación de Honduras, Tegucigalpa, 12 de diciembre de 1992.

83. Entrevista, San José, 18 de febrero de 1993. 
normales -económicas, sociales y culturales- de la sociedad, como en forjar e implementar la agenda nacional. Concebida de esta manera, la sociedad civil abarca todo, desde sindicatos hasta las "organizaciones no-gubernamentales", desde la Cruz Roja hasta las cámaras de comercio, desde "nuevos movimientos sociales" hasta organizaciones de etnias minoritarias, desde la iglesia católica hasta las sectas evangélicas. No existe consenso si la sociedad civil incluye a los partidos políticos. Una observación común es que mientras los sectores populares, desde el campesinado hasta los profesionales sin empleo y los que trabajan en el sector informal, buscan un "espacio" y una inserción en las nuevas condiciones del mercado bajo el ajuste, la sociedad civil "está llenando los espacios previamente ocupados por el Estado"84.

Distintos niveles de preparación y capacidad para llenar esos "espacios" se manifiestan en los diversos elementos de las sociedades civiles en Centroamérica. Los procesos de reestructuración social impulsados por los Programas de Ajuste Estructural, por la liberalización acelerada de las economías, y también por los conflictos violentos de los ochenta, según algunos observadores, han producido "sociedades fragmentadas": "La sociedad fragmentada es la condición de nuestros pueblos, tratados en contradicciones superficiales, desorientados respecto a objetivos comunes, imposibilitados de asumir luchas colectivas... la fragmentación implica una mayoría - y a veces el pueblo entero- que ha perdido el rumbo de su propia causa nacional"'8s. Aunque no es exactamente una condición postmoderna, la fragmentación es "una estrategia del poder dominante", del bloque hegemónico del capital oligárquico y transnacional, para restringir a la democracia e "imposibilita[r] la profundización de la democracia hacia formas populares y participativas, que por la misma lógica de la voluntad mayoritaria, harán de esas demo- cracias instrumentos de liberación... y III de d" pendencia" ${ }^{86}$. Esta interpretación del conceptu de la sociedad civil críticamente evalúa y rechurı lu imagen de las sociedades centroamericanas collno una recolección de "diferencias", de "minorías" y de "identidades". Por el contrario, se percata de que las mayorías experimentan, bajo el ajuste, nuevas y complejas formas de discriminación pero dentro del patrón clásico de divide et impera .

No obstante la experiencia común de la mayoría, existe una heterogeneidad de identidades sociales y cívicas que hacen difícil compartir un sentimiento de ciudadanía en las sociedades centroamericanas. Esta diferencia se ve impulsada por una variedad de dinámicas, incluso, el auge de autoconciencia y autoidentificación que caracteriza a muchos de los sectores populares, tanto los tradicionales como los "nuevos". La construcción de una ciudadanía predominante enfrenta la dinámica de reestructuración social bajo el ajuste, en la cual predominan la polarización y marginalización social. Esto favoreció la dislocación masiva de la población, la urbanización caótica y la emigración a Estados unidos durante los ochen$\mathrm{ta}^{87}$. Al mismo tiempo, la heterogeneidad y fragmentación hacen precisos el pluralismo y la tolerancia cívica.

En la práctica, como en los acuerdos de paz de la región, la concertación (definida como el diálogo y la cooperación entre diversos sectores sociales dirigidos a tareas concretas) refleja la prioridad de las agendas nacionales. La concertación es el medio donde se desarrolla la ciudadanía colectiva, pero también representa la entrega de los "bienes políticos" anteriormente negados a los sectores excluidos $^{88}$. Un buen ejemplo sobre el fenómeno es la concertación del sector empresarial, de los sindicatos y de los ministerios gubernamentales en $\mathrm{El}$ Salvador; juntos buscan evitar las confrontaciones que puedan romper las relaciones entre empresas y

84. Entrevista a Jorge Rivas, sociólogo, Universidad Nacional de Costa Rica, Heredia, 17 de febrero de 1993.

85. Binder, Alberto, "La Sociedad fragmentada", Pasos, No. Especial 3, San José: Departamento Ecuménico de Investigación, 1992, p. 23.

86. Ibid., p. 26.

87. La revista salvadoreña Tendencias manifiesta la postura de intelectuales centroamericanos respecto a las identidades posconflictos. Entrevista a Roberto Turcios, editor de Tendencias, San Salvador, 18 de marzo de 1993.

88. Para mayor información teórica y empírica sobre la concertación económica en la región, ver Menjívar Larín, Rafael, "Estado, trabajadores y patronos: concertación de intereses", Polémica. No. 14-15, San José: FLACSO, mayo-diciembre, 1991; del mismo autor, "La concertación en la estrategia de desarrollo de Centroamérica", en Stein y Arias Peñate, eds., op. cit., pp. 305-346. 
obreros. Incluso, hasta se ha venido elaborando una "teología de la concertación", en donde las identidades de creencia de la mayoría convergen con las experiencias de la reestructuración bajo los regímenes de los Programas de Ajuste Estructural y con las identidades diferenciadas y emergentes (de mujeres, de la juventud, de los grupos étnicos, del sector informal, etc.). En conjunto, la colección de identidades se convierte en un "nuevo sujeto social" reconstituido para un proyecto popular de liberación. Es una teología donde "lo espiritual pasa por la naturaleza, el trabajo, las mujeres y la juventud... buscando una nueva ética, una nueva conciencia, una reformulación espiritual", capaz de enfrentar los múltiples retos de la época actual ${ }^{89}$.

La creación de una cultura democrática que sostenga una sociedad civil sana y vibrante, es una función central de los movimientos populares. En general, los movimientos populares centroamericanos son definidos como las fuerzas sociales orientadas, objetiva y subjetivamente, hacia un cambio en las relaciones fundamentales de poder en beneficio de los sectores populares. Estos movimientos han experimentado una desmovilización relativa, una desarticulación y fragmentación de identidad bajo el ajuste y la reestructuración. Además, han sido afcctados por las crisis de la izquierda -discursivas e ideológicas, programáticas y organizativas ${ }^{90}$. Hoy en día, analistas y activistas pretenden superar los discursos analíticos alrededor de los sectores y movimientos populares. En csa tarea, la identidad, concebida en términos de conciencia de clase, cede, por un lado, a las identidades diferenciadas y móviles, y por el otro, a una ciudadanía más flexible. Los programas clásicos de la izquierda concernientes a la socialización económica y redistribución socialista dan prioridad a la producción para el mercado, a la adquisición de las necesidades básicas, la infraestructura social y la comunidad. Así, las prácticas y los patrones de vanguardismo, verticalismo y machismo se ven desafiados por unas islas de estilo inclusivo, participativo y no-jerárquico.

La sociedad civil busca a tientas la democratización genuina; la convicción queda, como insiste Helio Gallardo, en que "no habrá un verdadero porvenir sin un movimiento popular"9l. Durante los noventa, el balance constantemente perseguido y reajustado por los movimientos populares ha sido uno entre un "proyecto de liberación" redefinido y re-dinamizado y la política pragmática de participación en los distintos "pactos sociales", inscritos en las negociaciones regionales Esquipulas II, entendidos como las concertaciones necesarias para la reactivación económica92.

\section{8. ¿A quién le pertenece la agenda de acumula- ción?}

Según algunos analistas de la región, el presente y el futuro económicos parecen magros, tal vez peores que los de la década de los ochenta. Para ellos, es como si el "capitalismo salvaje", en su ropa particularmente moderna y azotadora, se haya desatado en el istmo. En palabras de Franz Hinkelammert: "en la visión del capitalismo salvaje, la exigencia de la reproducción del hombre y de la naturaleza [la sustentabilidad como las fuentes primarias de la vida, la riqueza y las economías] se transforma en un levantamiento en contra de la racionalidad, definida por las relaciones mercantiles [los mecanismos de la oferta y la demanda]" "9.3. De una manera algo más ligera, pero todavía crítica, Roberto Rubio expresa que el registro del crecimiento del Producto Bruto Nacional bajo el ajuste y la reestructuración "va paralelo con el aumento en la miseria y el deterioro de la calidad de vida de los ciudadanos... el concepto del 'mercado libre' gana adherentes mientras el 'mundo económi-

89. Citado de la entrevista, Pablo Richard, Departamento Ecuménico de Investigación (DEI), San José, 23 de febrero de 1993; entrevistas a Helio Gallardo y Franz Hinkelammert, DEI, 23 de febrero de 1993.

90. El tema de la reconstitución y la revisión de la izquierda política se encuentra frecuentemente en las ciencias sociales, entre los intelectuales y en los mismos movimientos populares en Centroamérica. Ver Marín, Raúl. “DDónde está su izquierda?”, Pensamiento Propio, No. 93, Managua: CRIES, agosto, 1992, pp. 21-28; y varios autores, “Opciones para la izquierda: ¿socialdemocracia o marxismo-leninismo?”, Tendencias, No. 25, San Salvador, noviembre, 1993, pp. 14-26.

91. Entrevista a Helio Gallardo, DEI, San José, 23 de febrero de 1993.

92. Peralta, Aguilera, "Camino de paz...", pp. 99-100.

93. Hinkelammert, Franz, "Las Tareas futuras...", en Stein y Arias Peñate, eds., op. cit., pp. 289-90. 
co' se contrae, con menos empresas y con millones de productores excluidos" 94 .

Dada la imposibilidad de volver política y económicamente a los regímenes torcidos de acumulación en Centroamérica, y con la aparente imposibilidad de establecer una economía socialista, ¿qué hacer?, parafraseando a alguien que ahora está fuera de moda. Como lo observan muchos, una "alternativa" ya está al mando; pero no es la alternativa imaginada por los revolucionarios centroamericanos, por una ciencia social radical, por los movimientos populares o por los socialdemócratas de las últimas trés décadas. La alternativa actual es una acelerada y universalizante concentración y centralización de capital (una dinámica doble en donde los marxistas por mucho tiempo han tratado de incorporar las cualidades inherentes del capitalismo) a nivel global.

Mientras esta "alternativa" sc desarrolle, los analistas centroamericanos, en su mayoría, han concentrado sus estudios sobre la crisis, el ajuste y la reestructuración en la mayor parte de la población. Por otro lado, consideran a esa mayoría de la población, definida como "sectores populares", de constituir, de una manera o de otra, el sujeto social histórico centroamericano. Manuel Solís ${ }^{95}$ sugiere que la misma noción de "sectores populares" lenía una premisa ideológica, esto es, que donde hay "masas" hay conciencia de masa y de clase y existe movimiento popular de masas. Una premisa más cautelosa e históricamente más informada se hace evidente ahora entre analistas y activistas: que tal conciencia y tales movimientos son sólo posibilidades, $y$ la medición de la probabilidad es una ciencia inexacla. Les ha quedado claro, pues, que una conciencia transclasista, pluralista o de masas populares, que dará luz a movimientos con un proyecto nacional de acumulación y de la ciudadanía, inclusive, como una "democracia sin pobreza", de ninguna manera está garantizada.

Así que tampoco deben sorprender las respueslas de los sectores populares ante la crisis económica, seguida por el ajuste y la reestructuración, las cuales han variado mucho en la región y dentro de países específicos. Durante los últimos veinte años, la militancia y la organización han coexlatfdo con y han cedido terreno a la desmovilización. el cansancio y la desorganización. Sin embargo. los espacios para la configuración de la sociedud civil, la producción, la identidad y la comunidad se han ampliado en muchos aspectos. Estos espacios serán arenas de respuesta y concertación, de conflicto y consenso, tanto en los noventa como en el siglo venidero: "una sociedad civil renascente, una con identidades múltiples y con facetas integradas, una no actualmente metida en la contención para el poder político, busca unos espacios en, y un impacto sobre, el mercado; una sociedad que presiona al Estado y enfrenta las influencias externas de Estados Unidos, de las transnacionales y de las instituciones financieras internacionales"96.

Aunque los noventa ciertamente no hayan sido los setenta o los ochenta, desde la perspectiva de la economía política como paradigma de las ciencias sociales, los elementos de las agendas nacionales centroamericanas relativos a la acumulación son familiares. Las contradicciones de los modelos y las experiencias de un desarrollo dependiente de la agroexportación contribuyeron fuertemente a las crisis económicas y políticas de las décadas previas. Se buscaron alternativas en cinco dimensiones: linanciamiento e inversión, producción, mercados, productores y consumo. Al considerarlas con amplitud, las alternativas lueron: diversificación, modernización, integración, inclusión y regionalización. Los objetivos de estas alternativas lueron reducir la dependencia, estabilizar y expandir la inserción de la región en los mercados globales, desarrollar las economías de cscala y de ventaja comparativa. Todo esto debía resultar de la integración económica regional, del aumento de la productividad y competitividad por la aplicación de la tecnología, de la más estrecha integración de los sectores disparejos de las respectivas economías nacionales, y de la inclusión de los marginados como productores eficaces. Irónicamente,

94. Rubio, Roberto, "Reconversión del pensamiento económico de cara al siglo XXI", Tendencias. No. 24, San Salvador, oclubrc. 1993, p. 14. En una entrevista, Rubio, director de investigación de FUNDE (Fundación Nacional para el Desarrollo), detalló su preocupación por la estabilidad social y política en El Salvador si el régimen de acumulación persistía en excluir a la mayoría, San Salvador, 18 de marzo de 1993.

95. Entrevista a Manuel Solís, Director del Instituto de Investigaciones Sociales, Universidad de Costa Rica, San José, 24 de febrero de 1993.

96. Entrevista a Pablo Richard, DEI, San José, 23 de febrero de 1993. 
estos objetivos generales eran comunes a tres perspectivas distintas: la de la izquierda, la de la burguesía "modernizadora" y la de los cuadros intelectuales de las instituciones financieras internacionales.

En la actualidad, según los críticos del neoliberalismo y de los Programas de Ajuste Estructural, esos objetivos se les han asignado exclusivamente a los mecanismos del mercado, en una "modernización" de la teoría "trickle-down" ["verter gota a gota'] de desarrollo. En la nueva ortodoxia del mercado, al Estado se le ha juzgado incapaz de alcanzar esos objetivos; mientras que los actores considerados capaces de lograrlos han sido las instituciones financieras internacionales, las corporaciones transnacionales y los grandes bloques de capital nacional. A partir de esta visión sobre las agendas nacionales, poco o ningún espacio se les otorga a los "pueblos", la sociedad civil o los sectores populares, cualquiera que sea la definición de la mayoría, para dibujar, dirigir o influenciar en la agenda. Con la experiencia de los Programas de Ajuste Estructural y la reestructuración, las expectativas del ciudadano centroamericano "ordinario", en palabras de Ramón Oquelí, historiador y comentarista hondureño, son que "cada año será peor"97. Aparentemente juzgada por la racionalidad del mercado, de que es una población sobrante e inútil, la mayoría de centroaméricanos, los sectores populares, seguirán constituyendo "la cuestión social", es decir, las agendas nacionales.

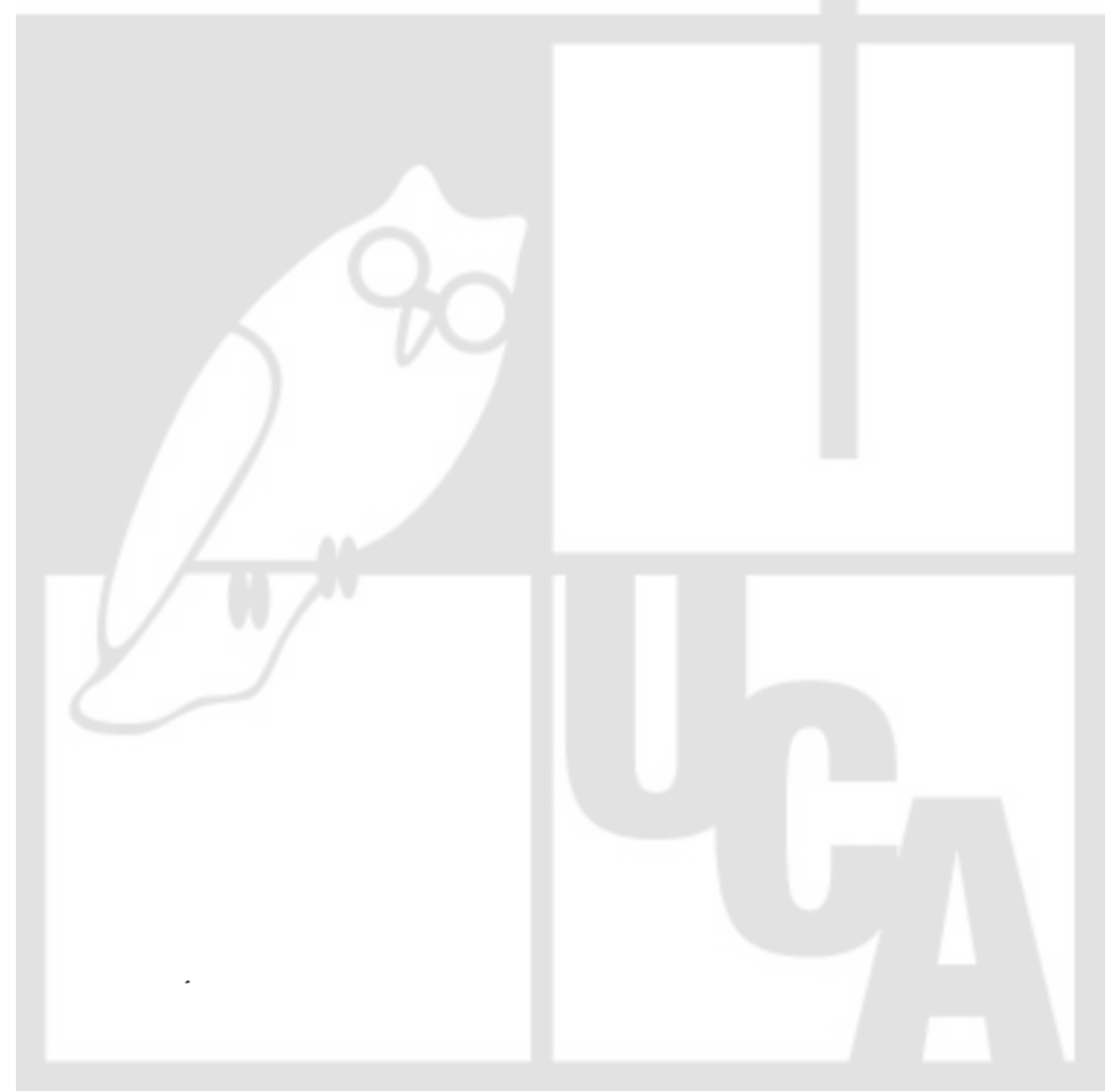

97. Entrevista, Tegucigalpa, 12 de noviembre de 1992. 